\title{
Seasonal precipitation interpolation at the Valencia region with multivariate methods using geographic and topographic information
}

\author{
Cristina Portalés, ${ }^{\mathrm{a} *}$ Nuria Boronat, ${ }^{\mathrm{a}}$ Josep E. Pardo-Pascual ${ }^{\mathrm{a}}$ and Angel Balaguer-Beser ${ }^{\mathrm{b}}$ \\ ${ }^{a}$ Dpto. Ing. Cartográfica, Geodesia y Fotogrametría, Universidad Politécnica de Valencia, Camino de Vera s/n, 46022 Valencia, Spain \\ ${ }^{\mathrm{b}}$ Dpto. Matemática Aplicada, Universidad Politécnica de Valencia, Camino de Vera s/n, 46022 Valencia, Spain
}

\begin{abstract}
The spatial pattern of precipitation is a complex variable that strongly depends on other geographic and topographic factors. As precipitation is usually known only at certain locations, interpolation procedures are needed in order to predict this variable in other regions. The use of multivariate interpolation methods is usually preferred, as secondary variables - generally derived using GIS tools - correlated with precipitation can be included. In this paper, a comparative study on different univariate and multivariate interpolation methodologies is presented. Our study area is centred in the region of Valencia, located to the eastern Spanish Mediterranean coast. The followed methodology can be divided in three steps. First, secondary variables having significant correlations with the precipitation were derived, where the hillsides were used as influence areas of certain variables. Secondly, precipitation was interpolated with different methodologies. Finally, the derived models were compared in terms of predicted errors. Models were achieved for seasonal scales, considering a total of 179 raingauges; data of another 45 raingauges were also used to predict errors. Results prove that there is no ideal method for all the cases but it will depend on one hand, on the number of geographical factors that influence the rainfall and, on the other hand, on the major or minor spatial correlation within the rainfall. Copyright (C) 2009 Royal Meteorological Society
\end{abstract}

KEY WORDS precipitation; multiple regression; geostatistics; topographic variables; digital elevation model

Received 29 September 2008; Revised 11 May 2009; Accepted 24 June 2009

\section{Introduction}

Rainfall is considered a highly valuable climatologic resource. Rainfall models have many uses, among others, long-term planning (Sboarina, 2002), climate change scenario construction (New et al., 2000), hydrological forecasting (Montecinos et al., 2000), hydro-chemical modelling, and human impact studies (Brezonik and Stadelmann, 2002). As a result, the assessment of water resources is often based on models interpolated from rainfall data (Dingman et al., 1988; Lanza et al., 2001). Several interpolation methods have been proposed and some authors have tried to identify the most reliable model overall that is able to describe the precipitation resource for a particular area. Traditionally, simple methods have been used, such as linear or quadratic approaches, for which the interpolated values are derived from the precipitation values at sample points. With the more powerful GIS and the inclusion of geostatistics toolkit into GIS (Burrough, 2001), improved methods which include secondary topographic and geographic information in the

\footnotetext{
* Correspondence to: Cristina Portalés, Dpto. Ing. Cartográfica, Geodesia y Fotogrametría, Universidad Politécnica de Valencia. Camino de Vera s/n, 46022 Valencia, Spain.

E-mail: criporri@upvnet.upv.es
}

interpolation procedures have been proposed, for example, multiple regression (MR) or cokriging approaches. This makes sense, since the relationship between precipitation and other variables is well described.

Precipitation is the result of lifting processes, which are driven by synoptic circulation, but the contribution of processes acting at lower scales is crucial. In particular the interaction of wind with surfaces and with the orography is fundamental in order to determine quantity, intensity, and distribution of precipitation events. The consequence is that the evaluation of the patterns of circulation and of their interactions with geography and morphology are fundamental in order to obtain realistic fields of precipitation. For instance, it is well known that precipitation usually increases with elevation or with the proximity to a body of water. Pardo-Igúzquiza (1998) compared the traditional Thiessen method with geostatistical ones to interpolate rainfall data at the Guadalhorce river basin (southern Spain), obtaining the best results for the kriging with external drift method, which included the elevation as secondary information. Goovaerts (2000) also used geostatistical algorithms to include elevation into the interpolation procedure in southern Portugal; Ninyerola et al. (2000) used a linear regression equation that included several topographical variables with correctors modelled by kriging estimators in the area 
of Catalunya (Spain); Wilk and Andersson (2000) compared a Thiessen based method with a regression based method for a mountainous river basin with monsoon climate (southern India), obtaining significant differences in seasonal rainfall analyses; Wotling et al. (2000) used stepwise regression - that included some topographical relief features - applied to a regular grid that was later interpolated with spline functions; Lin and Chen (2003) proposed a radial basis function network incorporating a semivariogram model to estimate rainfall distribution at the Tanshui river basin (Taiwan); Johansson and Chen (2003) found a regression model that included the wind variable for Sweden; Marquínez et al. (2003), used a regression model performed with topographic variables for Cantabria (Spain); Vicente-Serrano et al. (2003) concluded that the best results were obtained by geostatistical methods and a multiple regression (MR) model using four geographic and topographic variables for the central part of the Ebro Valley (Spain); Diodato and Ceccarelli (2005) compared the inverse squared distance method with linear regression and ordinary cokriging (OCK) for the Sannio Mountains (southern Italy), obtaining the best results for the cokriging that included the elevation as secondary information; finally, Diodato (2005) centers his study on Benevento's province (Italy), where the elevation factor is low correlated with the rainfall. He compares the methods of the ordinary kriging $(\mathrm{OK})$ and cokriging, using as secondary information a function that relates the level of greenery of the existing vegetation with the elevation, and concludes that the better results are for the cokriging approach.

Precipitation could be ideally described by physically based models taking into account the contribution of different scales (see Palmieri et al., 1994). Nevertheless, a geostatistical approach describes the effects of physical phenomena only in an empirical way, but it is probable that in the future the physically based approach will be crucial for a realistic geostatistical description of precipitation fields. The above-mentioned reference framework is the same adopted by experienced climatologists who draw precipitation isolines by hand on a map or by a professional meteorologist who makes a mesoscale forecast of precipitation in Mid Latitudes (Wetzel and Martín, 2001).

Clearly, a generally accepted methodology to model precipitation has not been found, and this seems to depend on the characteristics and size of the study area as well as on the available topographic variables and the considered temporal scale (daily, monthly, annually, etc.). In this paper, we study the relationship between precipitation and geographic and topographic variables to obtain an accurate precipitation distribution at our study area. Our study uses monthly rainfall means and considers seasonal temporal scales. The main research aims can be schematized as follows:

- Analysis and selection of geographic and topographic issues having significant correlation within precipitation.
- Definition of the optimal influence area of each geographic and topographic variable.

- Calculation and evaluation of different interpolation methods, including geostatistical approaches.

In first place, acquisition and filtering of precipitation data as well as geographical information have been carried out. Geographic and topographic variables have been derived using geographic information systems (GIS) after a study of the most suitable influence area for each of them. Secondly, the relationship between secondary variables and precipitation has been statistically analysed. Finally, four multivariate interpolation methodologies have been applied: MR, OK, regression with residual kriging, and OCK. Results are discussed and conclusions are given by means of statistic and cartographic analysis.

\section{Study area}

The study area is centred in the Valencia region (Figure 1), a Mediterranean coastal zone located in eastern Spain with an area of $23,255 \mathrm{Km}^{2}$. The physical geography of the region of Valencia is quite heterogeneous. It is divided into two main sectors: interior and coast. The first one is a mountainous area, integrated into the Iberic Range and the Prebetic and Subbetic Ranges. The highest altitudes of the studied area are about $1800 \mathrm{~m}$. The second sector is a littoral plain region, principally constituted by floodplains and alluvial fans, and a coastline formed by smooth beaches and coastal lagoons.

From the perspective of atmospheric dynamics it should be noted that the western Mediterranean, especially the maritime sectors of gulf of Genoa, Balearic Sea, gulf of Lion, and Alboran Sea, is a region with especial cyclogenetic activity due to the effective interaction between relief, disrupted air flows from the Atlantic and North Sea, and the thermal convective effect of seawater, especially in the autumn (Font Tullot, 1983; Pérez Cueva, 1994b; Jansá, 1996; Guijarro, 1997; MartínVide and Olcina-Cantos, 2001). Through this space about seventy depressions pass every year, being formed or being there reactivated many of them. Moreover, in this sector it is easy that cold drops are formed that arise from those that are formed in the Atlantic, opposite to the Portuguese coast or at north of the Canary Islands (HMSO, 1962). Within this space, the Valencian territory occupies a unique position because it is the only long coast facing the east, downwind of the Atlantic influence, which causes the detriment of rainfall but favours that the Mediterranean advection of air have the maximum possible path, which plays an important role in the genesis of the torrential rainfall that it receives (Pérez Cueva, 1994b; Armengot-Serrano, 2002). Perhaps the most characteristic feature of rainfall affecting the area of Valencia is the occurrence of heavy rainfall episodes. Between 1961 and 1990 there were categorized more than 176 situations where rainfall exceeded $100 \mathrm{~mm} /$ day. These episodes are associated with a disturbance in the middle and upper 


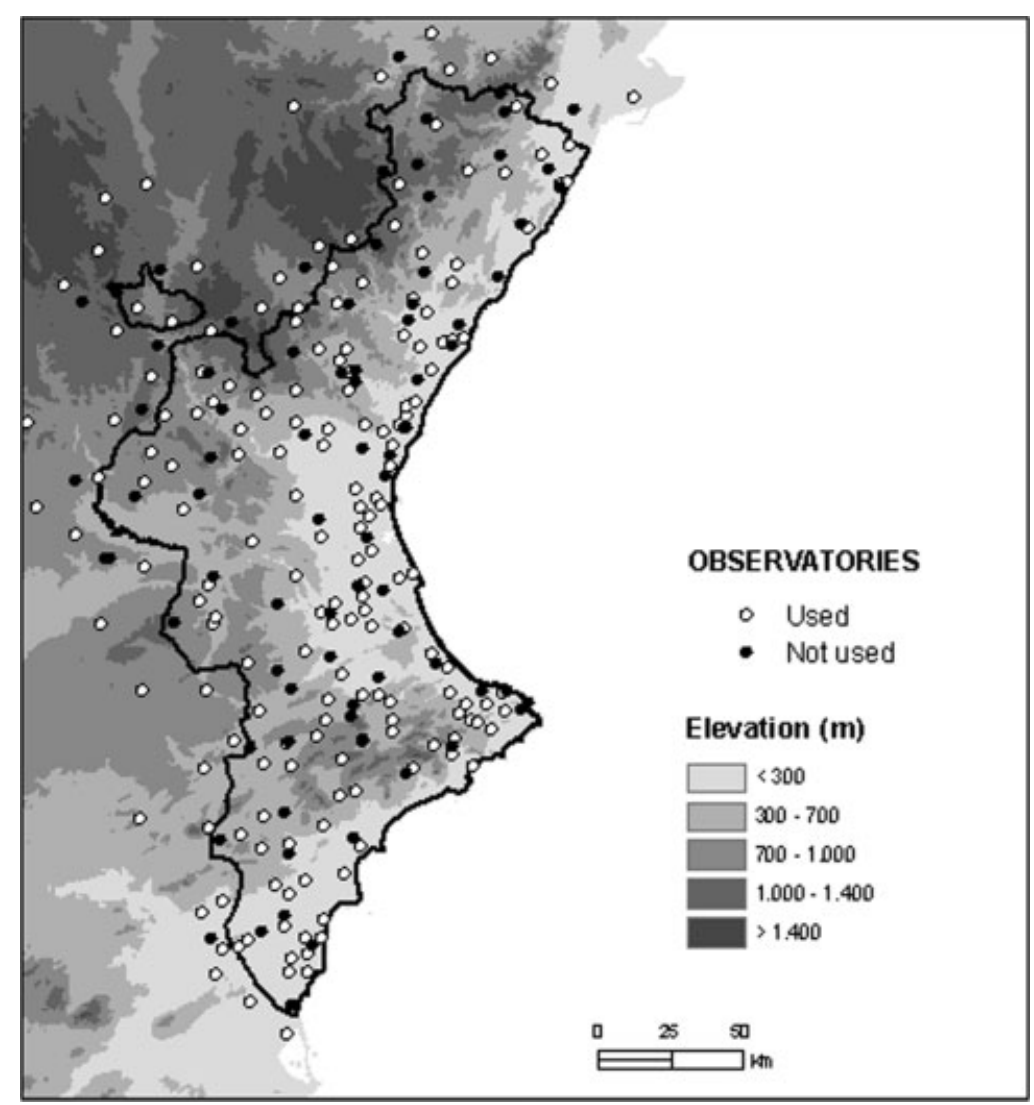

Figure 1. Raingauges superimposed to a digital elevation model.

troposphere by either a trough or a closed low with a core of cold air (Armengot-Serrano, 1994, 2002). This penetration of cold upper flows normally generates low surface pressures in the south-occidental Mediterranean that - usually associated with a Central European anticyclone - force east wind flows to be present in most of the episodes. This dynamic instability at high levels and in surface forms the basic overview of these situations, although its efficacy is modulated in response to other factors with a mesoscale character, both related to the characteristics and dynamics of the mass of air (divergence or difluence, the vorticity, the origin of the advection, temperature and humidity of the air mass, pressure gradient, etc.) as well as geographical factors such as relief or the heat marine field (Jansá et al., 1996; Riosalido, 1997; Riosalido et al., 1998; Rigo, 2004; Rigo and Llasat, 2007). Among the essential features of these storms it should be emphasized that the centre of action at high levels is crucial to explain the power of the episode, but the location of maximum rainfall is deeply influenced by the nature of the surface winds, combined with the direction of relief (Armengot-Serrano, 2002). Given the geographical position of the Valencian territory in the eastern margin of the Iberian Peninsula, rainfalls caused by advection from the west have, in general, a minor role (Peñarrocha, 1994) due to frontal systems that suffer from a gradual weakening as passing through its reliefs. During summer, most of the peninsula is often under the control of the anticyclone of the Azores, although at certain times cold air penetrations at upper levels may be produced, which can destabilize the atmosphere by favouring the formation of storms that will be more or less effective if they are accompanied by wet sea wind entries or the warming of the surface layers. The context that most favours these storms is the interaction between the topography and cold trough in upper levels (Alcover and Tamayo, 1994; Cano et al., 2001).

Climatologically, the Valencian region is slightly drier than the rest of the Mediterranean regions located at similar latitudes, since it is located to leeward of the west zonal flow. Therefore, the distribution of average rainfalls fluctuates greatly, with significant local variations related to multiple geographical factors. The greatest volumes - never very large as they do not exceed $850 \mathrm{~mm}$ per year - are found in two areas: where the Prebetic range approaches the coast - to the north of the Cap de la $\mathrm{Nau}-$ and in the northwestern area of the territory. The driest sector - for example, at a station with less than $250 \mathrm{~mm}$ per year - is located at the southernmost part of the region of Valencia. The rest of the territory registers intermediate values with local variations that cannot be explained by this single geographical factor.

\section{Sample data}

\subsection{Rainfall data}

Precipitation data comes from the raingauges of the National Institute of Meteorology network, grouped into 
monthly means for the period of 1960-2005, laying a total of 276 inside our study area. The World Metereological Organization (WMO) sets reference climate periods to unify and homogenize climate parameters world wide (Pérez Cueva, 1994a); the last is the period of 1961-1990 (De Luís et al., 2000; Price et al., 2000; Vadja and Venalainen, 2003). Nevertheless, a major period has been used in order to have a greater number of data when calculating mean values. Other authors have used longer or shorter series with satisfactory results (Hevesi et al., 1992; Goodale et al., 1998; Ninyerola et al., 2000; Marquínez et al., 2003; Vicente-Serrano et al., 2003). Data analysis shows several temporal and spatial lags, showing greater density at more populated areas, mainly corresponding to low areas close to the coast or to flat elevated areas at the interior. Therefore, only raingauges with more than 19 complete years were selected with the exception of one location - with only $16 \mathrm{com}$ plete years - because it is located at a mountainous area where all raingauges have shorter series. Raingauges having similar altitude and located closer than $2.5 \mathrm{~km}$ were grouped. Finally, a total of 224 raingauges were selected (see Figure 1), 145 of them having observations for 30 or more complete years. Nevertheless, interpolation methods were applied with only $80 \%$ of data (179 raingauges), reserving the rest (45 test raingauges) for validation purposes. The selection of these test raingauges was done in such a way that the remaining raingauges presented a maximum spatial similarity within the formers. The selecting method that better fulfilled this requirement was the one based on spatial criteria, ensuring that the whole area was analysed.

Afterwards, data were treated in order to palliate temporal discontinuity. To that purpose, uncompleted temporal series were filled with data from close reference raingauges having high correlation, similar altitude, and similar orientation to mountainous ranges. As reference raingauges were considered those having complete observed years (a total of 9 raingauges) or not more than two years with lack of data (35 raingauges), for the considered temporal period (1960-2005). Correlation coefficient between raingauges and corresponding reference raingauges has been in all cases greater than 0.7 , being greater than 0.8 in $84 \%$ of the cases.

Our study considers seasonal temporal scales; therefore, monthly rainfall means were grouped into the following variables: SPRI (spring: March, April, May), SUMM (summer: June, July, August), AUTU (autumn: September, October, November), and WINT (winter: December, January, February). Statistical analysis and histograms show non-normal data out of the $A N N U$, which are the sums of the other variables. Furthermore, in the case of WINT, kurtosis differs from that of the normal distribution.

In all seasons a great number of raingauges having low precipitations are observed, whereas there are a reduced number of raingauges having high or very high precipitations. Statistics are presented in Table I. The SUMM variable is a very dry season compared to the
Table I. Statistics for the annual and seasonal precipitation means for the 224 raingauges.

\begin{tabular}{lrrrrr}
\hline Statistics & SPRI & SUMM & AUTU & WINT & ANNU \\
\hline Average & 128.26 & 66.59 & 172.77 & 123.94 & 491.56 \\
\hline Stnd. deviation & 32.83 & 26.70 & 51.83 & 46.16 & 134.41 \\
Minimum & 60.78 & 17.71 & 83.40 & 54.70 & 233.30 \\
Maximum & 223.14 & 144.07 & 305.44 & 273.81 & 847.66 \\
Range & 162.36 & 126.35 & 222.04 & 219.11 & 614.36 \\
Skewness & 2.05 & 3.28 & 2.63 & 6.30 & 1.55 \\
Kurtosis & 0.07 & -0.43 & -0.99 & 2.63 & -0.40 \\
\hline
\end{tabular}

other seasons and therefore, it has a low correlation with them as well as with the annual precipitation. The difference between the behaviour of SUMM and the rest of the year is explained by meteorological factors, specifically, that during this season the study area is most of the time under the influence of the Azores anticyclone, producing fundamentally rains of a convective nature associated with a weakening of the anticyclonic situation allowing the penetration of cold flows at upper levels that, along with the surface warming of the station itself and the penetration of moist air from the Mediterranean surface, facilitates the formation of storms. For the rest of the year, the rains are usually associated with low pressures related to the zonal flow of the West, reactivated in the Mediterranean Sea, as has been previously exposed. The highest precipitation values are registered in $A U T U$, whereas SPRI and WINT variables have a similar average but the variance is higher in WINT.

For more than a decade, to the data measured by meteorological observatories, complementary information coming from other instruments (e.g., remote sensing from satellite, radar maps and information from lighting detection systems) can be added (see for example, New et al., 2001; Islam et al., 2002; Su et al., 2008). We have considered the possibility to fill the temporary series by means of the TRMMbased precipitation estimates, which are available for the research community at the following web site: http://daac.gsfc.nasa.gov/data/datapool/TRMM/01_Data_ Products/02_Gridded/index.html. The global rainfall algorithm (3B43.v6) combines the estimates generated by combined instrument rain calibration and global gridded raingauge data. The output is rainfall for $0.25 \times 0.25$ degree grid boxes for each month in the intervals of latitude $50^{\circ} \mathrm{S}-50^{\circ} \mathrm{N}$ and longitude $180^{\circ} \mathrm{W}-180^{\circ} \mathrm{E}$. The starting date is 1998-01-01. TRMM 3B43.v6 precipitation estimates provide a total of 72 data for our study area. In Figure 2(a), distribution is observed as compared to the situation of the 224 meteorological raingauges with useful information. It can be seen that - except for three sectors identified by the letters A, B, C - there is information from one or more raingauges at each sector.

To compare the records measured in observatories and estimates from the TRMM 3B43.v6 data, all raingauges located within each sector have been located, and average 

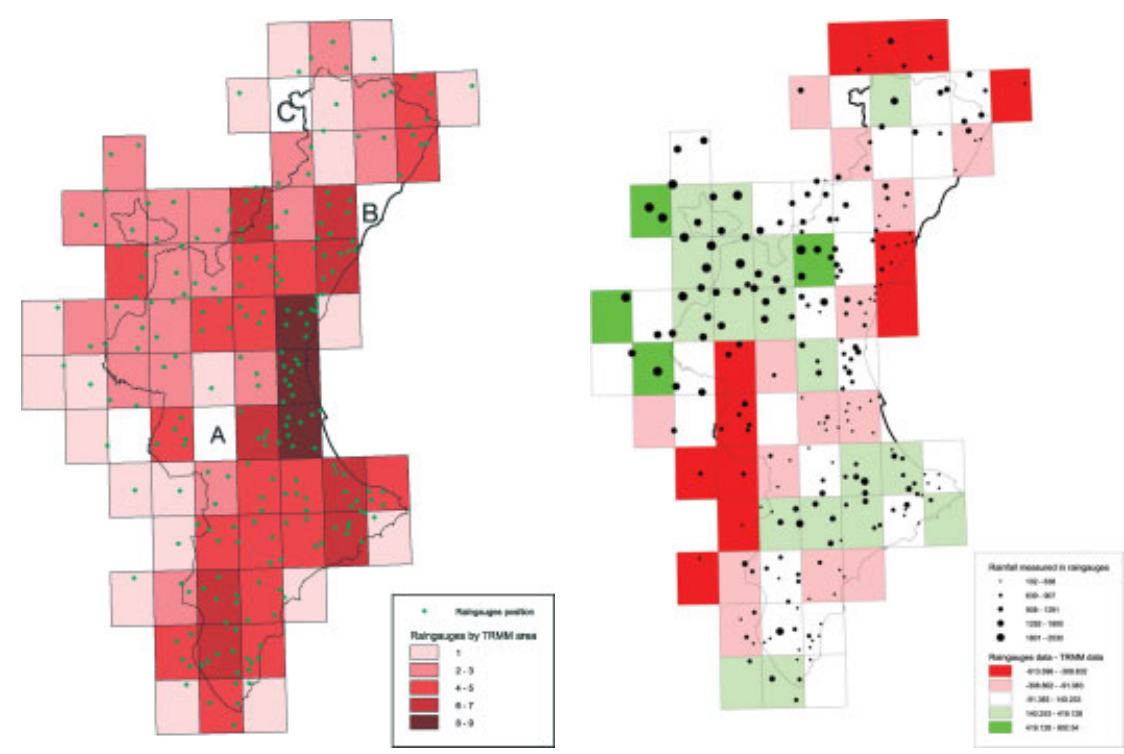

Figure 2. Comparison of TRMM 3B43.v6 data and raingauges data, where: (a) Raingauges superimposed to TRMM 3B43.v6 data. (b) Differences between rainfall data and TRMM 3B43.v6 precipitation estimates for spring 1998. This figure is available in colour online at www.interscience.wiley.com/ijoc

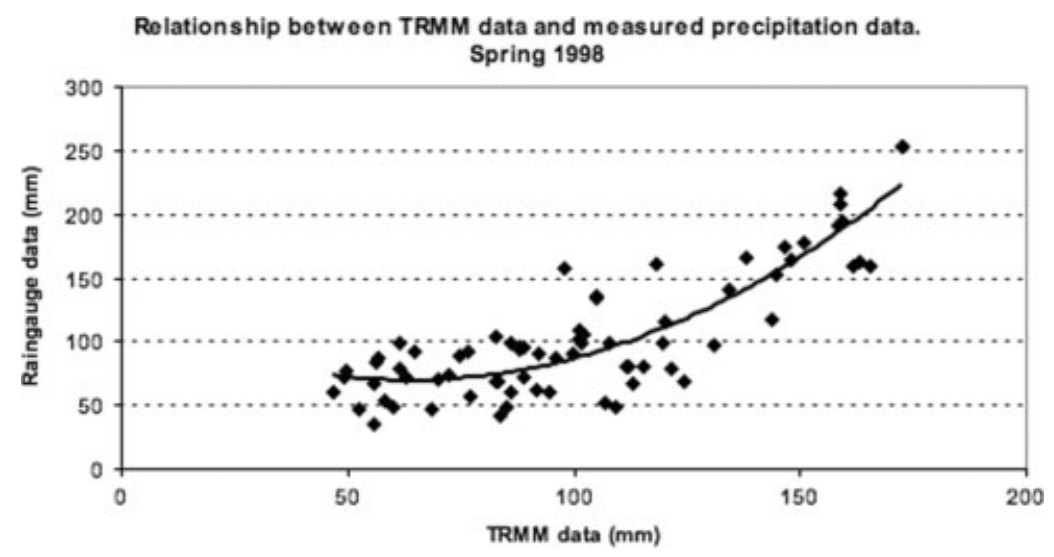

Figure 3. Scattergram of precipitation from averaged raingauge data and TRMM 3B43.v6 estimates for spring 1998.

rainfall has been obtained. The difference between this value and the corresponding data on the TRMM 3B43.v6 spring 1998 is shown in Figure 2(b). This figure also shows the amount of rainfall recorded at each raingauge. It can be observed that the greatest differences occur at the edges of the study area where there are fewer raingauges. This follows the findings reported in $\mathrm{Su}$ et al. (2008), which ensures that TRMM 3B43.v6 data tend to provide slightly larger estimates than that provided by the raingauge data; this difference is interpreted as mostly reflecting the climatological undercatch correction applied to TRMM data (Huffman et al., 2007).

Figure 3 shows the scattergram of precipitation from averaged raingauges data and TRMM 3B43.v6 estimates for spring 1998. The best fit - with a determination coefficient of $r^{2}=0.72$ - has been achieved through an equation of the second degree. This shows that the differences are exaggerated in the highest and lowest TRMM values.

Despite this, the difference between the average of the 224 raingauges and the average of the TRMM 3B43.v6 data is about $0.4 \mathrm{~mm}$. On the other hand, although there are 11 raingauges with rainfall exceeding $200 \mathrm{~mm}$, all TRMM data keep below $175 \mathrm{~mm}$. Similarly, there is a raingauge with $10.2 \mathrm{~mm}$, whereas the minimum value of TRMM B43.v6 is $44.8 \mathrm{~mm}$. In this way, data from the raingauges are able to show the differences in precipitation that occur at small spatial scales, which is not true for the TRMM B43.v6 estimates. Additionally, with regard to temporal scale, data from raingauges cover the period 1960-2005, while the TRMM 3B43.v6 data are only available since 1998. For these reasons, it was therefore decided to complete the time series with the reference stations instead of the TRMM B43.v6 estimates. However, this comparison with satellite data has been used to verify the validity of our data.

\subsection{Geographical and topographical variables}

It is well known that some variables derived from topography and geography have some influence on precipitation (Barry and Chorley, 1984). For example, although 
due to complexities of the precipitation process there are many exceptions to simple rules (Andersson, 1980), precipitation usually increases with elevation and several authors have introduced this into geostatistical interpolation methods (Goovaerts, 2000; Ninyerola et al., 2000; Brunsdon et al., 2001; Johansson and Chen, 2003; Marquínez et al., 2003; Vicente-Serrano et al., 2003; Diodato and Ceccarelli, 2005). Other variables having an effect on precipitation are the longitude and latitude (having positional effects in our case), relief, slope, aspect, and distance to the sea. Therefore, taking these variables into account, an improvement of the rainfall prediction is expected. To this effect, one of our main goals was to find out which variables have an important influence on the rainfall in the region of Valencia.

In this study we consider in first place the influence of certain topographical and geographical variables (referred as secondary variables) on the precipitation pattern of the study area, deriving a total of 25 variables (Table II). These variables were derived from the digital elevation model (DEM), the map of superficial flows, and the map of hillsides. The map of superficial flows was as derived by Armengot-Serrano (1993) who, in his

Table II. Meaning of geographical and topographical variables.

\begin{tabular}{ll}
\hline Variable & \multicolumn{1}{c}{ Meaning } \\
\hline$X$ & $\begin{array}{l}\text { Longitude in the UTM coordinate system. } \\
\text { Latitude in the UTM coordinate system. }\end{array}$ \\
RONT20 & $\begin{array}{l}\text { Ratio between the land/sea surfaces inside a } \\
\text { circular area of } 20 \mathrm{~km} \text { radius around each pixel } \\
\text { Ratio between the land/sea surfaces inside a } \\
\text { circular area of } 50 \mathrm{~km} \text { radius around each pixel }\end{array}$ \\
COAST & $\begin{array}{l}\text { Minimum distance to the Mediterranean Sea } \\
\text { Mean elevation inside a circular area of } 5 \mathrm{~km}\end{array}$ \\
Z10 & $\begin{array}{l}\text { radius around each pixel } \\
\text { Mean elevation inside a circular area of } 10 \mathrm{~km} \\
\text { radius around each pixel }\end{array}$ \\
Mean slope inside a circular area of $5 \mathrm{~km}$ \\
radius around each pixel
\end{tabular}

Table II. (Continued).

Variable Meaning

$V S \_$(Normalized scalar product of the vector of North direction and the vector of synoptic flow direction on surface +1$) / 2$

VS_E1 (Normalized scalar product of the vector of East direction and the vector of synoptic flow direction on surface +1$) / 2$

$V A \_N 1 \quad$ (Normalized scalar product of the vector of North direction and the vector of synoptic flow direction on $850 \mathrm{hPa}+1) / 2$

VA_E1 (Normalized scalar product of the vector of East direction and the vector of synoptic flow direction on $850 \mathrm{hPa}+1) / 2$

SUPDIF Elevation difference between the highest point of a hillside and the highest point inside an area oriented within the synoptic flow direction on surface

SUPDISTF Distance between the hillside centroide and the highest point inside an area oriented within the synoptic flow direction on surface

SUPDIFDIS SUPDIF/SUPDISTF

ALTDIF Elevation difference between the highest point of a hillside and the highest point inside an area oriented within the synoptic flow direction on $850 \mathrm{hPa}$

ALTDISTF Distance between the hillside centroide and the highest point inside an area oriented within the synoptic flow direction on $850 \mathrm{hPa}$

ALTDIFDIS ALTDIF/ALTDISTF

study of intense precipitations at the region of Valencia, obtained the mean vectors of the synoptic flows on the surface and on $850 \mathrm{hPa}$, and sub-divided the territory into 15 sectors according to physical homogeneity and raingauges localization. The spatial analyses have been carried out within the ArcGIS 9.0 software, including the calculation of variables and the generation of distribution precipitation models. Some scripts were also created in order to automate certain processes.

According to Daly et al. (1994) the geographical and topographical elements to the scale of 2-15 km are better correlated within precipitation than punctual elements. Therefore, mean values of elevation $(Z 5, Z 10)$, slope $(S 5, S 10)$, and height difference $(D 5, D 10)$ were derived inside certain areas, in this case, circular buffers. Several tests were carried out considering radii of $1,2.5,5$, and $10 \mathrm{Km}$ for all of the variables. Finally, the buffers of 5 and $10 \mathrm{Km}$ radii were selected because they led to higher correlations with the precipitation variables. As described by Wotling et al. (2000), this permits the smoothing of the local effects and the better integration of the main features of the topographical environment.

The hillsides were used as influence area of certain variables. Some authors, as Marquínez et al. (2003), have used the sub-basins as influence areas. Other works, like the ones developed for the PRISM model (Gibson et al., 1997; Daly et al., 2002), have also used the units of 
hillslopes as influence areas to evaluate the repercussion of the exposure to some humid flows differentiating the areas of windward and leeward, though they have followed a substantially different methodology (Gibson et al., 1997; Sotillo et al., 2003). In this paper, areas defining hillsides were automatically derived within VESSANTS, a software developed by the Geoenvironmental Cartography and Remote Sensing research group of the Polytechnic University of Valencia. The method that we have used - described in more detail in Capdevilla et al. (2003) and Palomar et al. (2005)-consists of obtaining the basins and drainage networks by means of standard algorithms implemented in a GIS (in this case ArcView 3.2). Then, by means of a specific program, the fluvial channel is elongated upstream following the line of maximum accumulation, until the basin divide is reached, in such a way that every basin is divided into two hillsides by the river.

To calculate the aspect variable $(A)$ the hillsides were used as influence areas; thus all locations belonging to the same hillside are considered to have the same aspect vector. Nevertheless, previously to its calculation, the planar areas were extracted. As a result of some tests, those areas having a slope smaller than the $3 \%$ were considered to be flat. To those areas the aspect value of the closest area was assigned. The map of superficial and upper flows (Armengot-Serrano, 1993) was used in order to define the variables VSNI, VSEE1, VA NI, and VAEI due to the close relationship between these flows, the relief structural axes, and the precipitation intensity. These maps were created from the study of weather maps - isobars on the surface and its topography at $850 \mathrm{hPa}$ - for the 176 rainfall episodes that exceeded the $100 \mathrm{~mm}$ in a single event (Armengot-Serrano, 1993).

The variables having an angular character, as the aspect or the direction of synoptic flows, needed a linearization to be introduced in the equations. To that purpose, the normalized scalar product between the variable and the North and East directions were computed. Finally, a transformation was applied in such a way that the resulting value lay between 0 and 1 .

In the analysis carried out by Johansson and Chen (2003), the most relevant singular variable was the location of the raingauges in relation to a mountain range. In our study, a new group of variables (SUPDIF, SUPDISTF, SUPDIFDIS, ALTDIF, ALTDISTF, and ALT$D I F D I S$ ) was added in order to solve the problem of the precipitation shadows. We proceed as follows: a script was written within the Phyton language and introduced into the ArcGIS software in order to automatically calculate, from the centroide of each hillside, the highest point inside an area (Figure 4) oriented according to the synoptic flow on surface or on $850 \mathrm{hPa}$ corresponding to the centroide. Within the coordinates and the elevation of the highest point and the centroide, the distance between them (variables SUPDISTF and ALTDISTF) as well as the height difference (variables SUPDIF and ALTDIF) can be calculated. The relation between them (variables

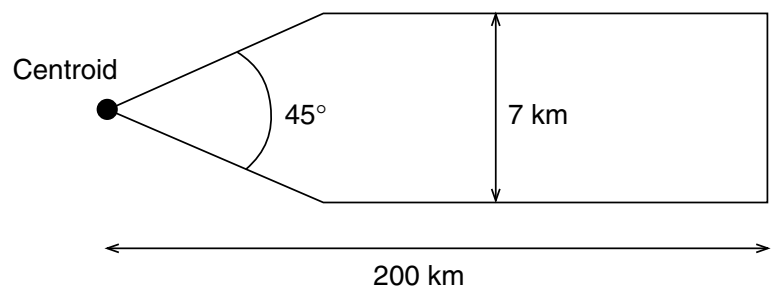

Figure 4. Sector used to obtain the coordinates and elevation of the highest point in the synoptic flow direction.

SUPDIFDIS and ALTDIFDIS) measures the effect of the orographic barrier.

Additional variables were calculated from squared and cross products between each pair of secondary variables, due to the fact that the relationship between precipitation and independent topographical secondary variables generally is closer to quadratic or cubic models than to lineal ones (Marquínez et al., 2003); furthermore, the combination of two variables can bring more information than considering them independently, as is the case of the product of the direction of synoptic flows and elevation.

\section{Interpolation procedures}

We consider three multivariate methods which use the secondary information provided by the variables described in section 2.2. We compare the obtained results with the computed ones using an OK method which considers only the rainfall at sample locations.

\subsection{Multiple regression (MR)}

Within the MR procedure, the rainfall variable $Z(u)$ in a location $u$, with the observed data $\left\{z\left(\mathbf{u}_{\alpha}\right), \alpha=\right.$ $1, \ldots, n\}$, is predicted by $N_{v}$ continuous attributes $Y_{i}(u)$, considering the information available at all estimation points $\left\{y_{i}\left(\mathbf{u}_{\alpha}\right), \alpha=1, \ldots, n, i=1, \ldots, N_{v}\right\}$. The value of a variable $Z_{\mathrm{MR}}^{*}$ at unsampled points is predicted by the following Equation (1) (Goovaerts, 2000; VicenteSerrano et al., 2003):

$$
z_{\mathrm{MR}}^{*}(\mathbf{u})=a_{0}+a_{1} y_{1}(\mathbf{u})+a_{2} y_{2}(\mathbf{u})+\ldots+a_{N_{v}} y_{N_{v}}(\mathbf{u})
$$

where the $a_{0}, \ldots, a_{N_{V}}$ are the regression coefficients and $y_{1}(\mathbf{u}), \ldots, y_{N_{v}}(\mathbf{u})$ are the values of the different independent variables at location $\mathbf{u}$.

The MR procedure was carried out by using the STATGRAPHICS software. Considering all the secondary variables described in Table II and their square and cross products, the total number of variables (350) was greater than the amount of rainfall data (179). To reduce the number of variables the following steps were taken:

1) First Step: After a visual inspection of all derived statistics (scatterplots, histograms, correlation coefficient), only those variables that are significantly correlated (in general at the 95\% confidence level) with precipitation were considered. With this procedure, 
the number of selected variables was: 189 for SPRI, 194 for SUMM, 215 for AUTU, and 159 for WINT.

2) Second Step: Considering the group of variables selected in the first step (named G1), we introduce these variables in the regression model by means of the following forward process:

2.1) We consider the subgroup of variables of G1 defined by the $X$ variable, its square and cross products with other variables (subgroup G1X). We introduce this subgroup in the regression model and then apply a backward selection method in order to reduce the number of variables, thus simplifying the regression equation. In the obtained model we also eliminate the variables which may give the same information; for example, we choose one variable between $X \cdot Z 5$ and $X \cdot Z 10$. We also analyse the contribution of each variable to the $R^{2}$ coefficient of the regression model; thus we eliminate the variables that do not entail an improvement in the $R^{2}$ coefficient.

2.2) We consider the subgroup of variables of G1 defined by the $Y$ variable, its square and cross products with other variables (subgroup G1Y), with the exception of $X \cdot Y$ (considered in the previous step 2.1). We add this subgroup to the regression model obtained in the step 2.1 and then apply a backward selection method in order to reduce the number of variables. Again we choose one variable from the subgroup which may give the same information to the model and eliminate the variables that do not significantly improve the $R^{2}$ coefficient.

2.3) We use the same procedure of steps 2.1) and 2.2) for the other 23 variables described in Table II.

3) Third Step: We analyse the residuals in the regression model in order to detect a possible autocorrelation. For example, we observe the variation of the DurbinWatson statistic when we introduce a new subgroup of variables in the model. Moreover, we want to obtain a regression model whose $R^{2}$ coefficient is higher than 0.75 needing the lesser number of variables.

As a result of steps 2) and 3), the number of variables (and $R^{2}$ ) was: $9(0.80)$ for SPRI, $4(0.88)$ for SUMM, 12 (0.86) for AUTU, and 18 (0.83) for WINT.

\subsection{The OK method}

The kriging interpolation is based on the assumption that the parameter being interpolated can be treated as a regionalized variable (Goovaerts, 1997). In the weighting function, the semivariogram is used as a measure of dissimilarity between observations. The experimental semivariogram $\hat{\gamma}(\mathbf{h})$ is computed as half the average squared difference between the components of data pairs:

$$
\hat{\gamma}(\overrightarrow{\mathbf{h}})=\frac{1}{2 N(\overrightarrow{\mathbf{h}})} \sum_{\alpha=1}^{N(\overrightarrow{\mathbf{h}})}\left[z\left(\mathbf{u}_{\alpha}\right)-z\left(\mathbf{u}_{\alpha}+\overrightarrow{\mathbf{h}}\right)\right]^{2}
$$

where $N(\overrightarrow{\mathbf{h}})$ is the number of pairs of data separated by a vector $\overrightarrow{\mathbf{h}}$ within a certain tolerance angle. In this paper the experimental semivariograms were computed by using the Geostatistical Analyst module of ArcMap (Johnston et al., 1997), and the obtained results were corroborated within the program VARIOWIN 2.2 (Pannatier, 1996; Mardikis et al., 2005). We have used a lag size equal to $10000 \mathrm{~m}$. and a number of lags equal to 18 . Then, the theoretical semivariogram models were defined taking into account the experimental behaviour near the origin and farther away. In some cases anisotropies were considered.

Once the semivariogram models are defined, the kriging interpolation can be performed. All kriging estimators are variants of the basic linear regression estimator $z^{*}(\mathbf{u})$, which is defined as (Goovaerts, 1997)

$$
z^{*}(\mathbf{u})-m(\mathbf{u})=\sum_{\alpha=1}^{n(\mathbf{u})} \lambda_{\alpha}(\mathbf{u})\left[z\left(\mathbf{u}_{\alpha}\right)-m\left(\mathbf{u}_{\alpha}\right)\right]
$$

where $n(\mathbf{u})$ is the number of neighbouring observations and $\lambda_{\alpha}(\mathbf{u})$ is the weight assigned to $z\left(\mathbf{u}_{\alpha}\right)$ interpreted as a realization of the random variable $Z\left(\mathbf{u}_{\alpha}\right)$. The values $m(\mathbf{u})$ and $m\left(\mathbf{u}_{\alpha}\right)$ are the expected values of the random variables $Z(\mathbf{u})$ and $Z\left(\mathbf{u}_{\alpha}\right)$. Several kriging variants can be distinguished according to the model considered for the trend $m(\mathbf{u})$ (Deutsch and Journel, 1998; Goovaerts, 1997). In this paper we have used the Ordinary Kriging (OK).

In order to choose the best-fit variogram model we also have used the cross-validation method, evaluating the error of the OK method by means of the five error statistics that offer the Geostatistical Analyst module of ArcMap: the mean prediction error, the root mean square prediction error, the average kriging standard error, the square standardized prediction error, and the root mean square statndardized prediction error. More details of these statistics can be found in Evrendilek and Ertekin (2008).

\subsection{MR with residual kriging (MRK)}

The regression residuals were kriged in order to correct for any local overestimation or underestimation (Prudhomme and Reed, 1999; Agnew and Palutikof, 2000; Ninyerola et al., 2000). OK was used in this case and exponential or spherical semivariograms were used. This methodology may be described by the following steps:

1) We compute the residuals of the MR model described in section 2.1:

$$
r\left(u_{\alpha}\right)=z_{\mathrm{MR}}^{*}\left(u_{\alpha}\right)-z\left(u_{\alpha}\right), \quad \forall \alpha=1, \cdots, n
$$

2) We apply an $\mathrm{OK}$ method to this residuals so that we obtain an estimation of the residuals $\widehat{r}(u)$ in each location $u$. In this paper we have considered exponential models for the semivariogram of SPRI, 
$A U T U$, and WINT variables. For the SUMM variable we have used a spherical model.

3) We compute the following estimation:

$$
z_{\mathrm{MRK}}^{*}(u)=z_{\mathrm{MR}}^{*}(u)-\widehat{r}(u)
$$

\subsection{Ordinary cokriging (OCK)}

The linear estimator of Equation (3) is extended to incorporate additional information (Goovaerts, 1997):

$$
\begin{aligned}
& z_{1}^{*}(\mathbf{u})-m_{1}(\mathbf{u})=\sum_{\alpha_{1}=1}^{n_{1}(\mathbf{u})} \lambda_{\alpha_{1}}(\mathbf{u})\left[z_{1}\left(\mathbf{u}_{\alpha_{1}}\right)-m_{1}\left(\mathbf{u}_{\alpha_{1}}\right)\right] \\
& +\sum_{i=2}^{N_{v}} \sum_{\alpha_{i}=1}^{n_{i}(\mathbf{u})} \lambda_{\alpha_{i}}(\mathbf{u})\left[z_{i}\left(\mathbf{u}_{\alpha_{i}}\right)-m_{i}\left(\mathbf{u}_{\alpha_{i}}\right)\right]
\end{aligned}
$$

where $\lambda_{\alpha_{1}}(\mathbf{u})$ is the weight assigned to the primary datum $z_{1}\left(\mathbf{u}_{\alpha_{1}}\right)$ and $\lambda_{\alpha_{i}}(\mathbf{u}), i>1$, is the weight assigned to the additional data $z_{i}\left(\mathbf{u}_{\alpha_{i}}\right)$. The quantities $m_{1}(\mathbf{u})$ and $m_{i}\left(\mathbf{u}_{\alpha_{i}}\right)$ are the expected values of the random variables $Z_{1}(\mathbf{u})$ and $Z_{i}\left(\mathbf{u}_{\alpha_{i}}\right)$.

The cokriging accounts for the spatial correlation between variables as captured by the cross-semivariogram or cross-covariance. The Geostatistical Analyst module of ArcMap uses the cross-covariance for geostatistical multivariate models that for two variables $\left(z_{1}, z_{2}\right)$ can be written as

$$
\hat{C}_{12}(\overrightarrow{\mathbf{h}})=\frac{1}{N(\overrightarrow{\mathbf{h}})} \sum_{\alpha=1}^{N(\overrightarrow{\mathbf{h}})} z_{1}\left(\mathbf{u}_{\alpha}\right) \cdot z_{2}\left(\mathbf{u}_{\alpha}+\overrightarrow{\mathbf{h}}\right)-m_{z_{1}} \cdot m_{z_{2}+\overrightarrow{\mathbf{h}}}
$$

where

$$
\begin{gathered}
m_{z_{1}}=\frac{1}{N(\overrightarrow{\mathbf{h}})} \sum_{\alpha=1}^{N(\overrightarrow{\mathbf{h}})} z_{1}\left(\mathbf{u}_{\alpha}\right) \quad \text { and } \\
m_{z_{2}+\overrightarrow{\mathbf{h}}}=\frac{1}{N(\overrightarrow{\mathbf{h}})} \sum_{\alpha=1}^{N(\mathbf{h})} z_{2}\left(\mathbf{u}_{\alpha}+\overrightarrow{\mathbf{h}}\right)
\end{gathered}
$$

As in the kriging approach, several cokriging variants can be distinguished according to the trend model $m_{i}(\mathbf{u})$ (Goovaerts, 1997; Deutsch and Journel, 1998). In this paper the OCK estimator is considered. Only one secondary variable - which, in fact, took into consideration more secondary variables - was introduced. This new variable is made up of the predicted values of the MR method with residual kriging (MRK) calculated in the previous subsection. Using this variable, the interpolation procedure was simplified and the resulting cokriging models were enriched.

\section{Results}

In this section it is presented, in first place, the correlations between the geographical/topographic variables and the registered values of mean rainfall on every station. Taking these results as a base, DRMs have been obtained by applying different interpolation methods. Finally, results of the statistical evaluation on each of the proposed models are shown.

5.1. Relationship between precipitation and secondary variables

Results in Table III show that the correlation between most of the secondary variables and the precipitation is only statistically significant for some of the seasons, not for all of them. In general, the secondary variables that have the highest correlations with precipitation are $X, Y, S 5, S 10, C_{-} N 1$, and $C_{-} E$. Other variables are more significant at the scalar products, as is the case of the variables derived form the synoptic flows ( $\left.V S \_N 1, V S \_E, V A \_N 1, V A \_E\right)$. None of the variables related with the orographic rainfall shadows (SUPDIF, SUPDISTF, SUPDISDIS, ALTDIF, ALTDISTF, and ALT$D I F D I S$ ) shows a significant correlation with precipitation, even when they are used as scalar products within other variables.

\subsection{Obtained models}

The linear regression models obtained for the annual and seasonal precipitation are shown in Table IV. We observe that the elevation (Z5 or Z10) only appears in the SPRI and $S U M M$ models and within the product with other variables. The variables $X, Y$, and $V S \Lambda 1$ appear in all

Table III. Correlation coefficients between geographical/ topographical variables and the precipitation.

\begin{tabular}{lrrrr}
\hline Variables & \multicolumn{4}{c}{ Correlation coefficient } \\
\cline { 2 - 5 } & SPRI & SUMM & AUTU & WINT \\
\hline$X$ & 0.29 & -0.03 & 0.64 & 0.38 \\
CONT20 & 0.40 & 0.83 & 0.31 & 0.06 \\
CONT50 & 0.14 & 0.35 & -0.27 & -0.13 \\
COAST & -0.02 & 0.47 & -0.45 & -0.36 \\
Z5 & 0.13 & 0.53 & -0.37 & -0.18 \\
Z10 & 0.32 & 0.71 & -0.22 & -0.07 \\
S5 & 0.31 & 0.72 & -0.22 & -0.08 \\
S10 & 0.56 & 0.45 & 0.25 & 0.36 \\
D5 & 0.58 & 0.51 & 0.28 & 0.36 \\
D10 & 0.48 & 0.26 & 0.22 & 0.33 \\
A_N1 & 0.46 & 0.34 & 0.23 & 0.27 \\
A_E1 & 0.20 & 0.07 & 0.21 & 0.20 \\
C_N1 & -0.03 & 0.02 & -0.03 & -0.06 \\
CEE & 0.25 & -0.18 & 0.38 & 0.46 \\
VS_N1 & -0.30 & 0.02 & -0.32 & -0.33 \\
VS_E & 0.19 & -0.46 & 0.21 & 0.49 \\
VA_N1 & -0.15 & -0.45 & -0.19 & 0.12 \\
VA_E & -0.02 & -0.54 & -0.11 & 0.22 \\
SUPDIF & -0.18 & -0.54 & -0.26 & 0.08 \\
SUPDISTF & -0.04 & 0.02 & -0.21 & -0.10 \\
SUPDIFDIS & 0.11 & 0.13 & -0.16 & -0.01 \\
ALTDIF & -0.02 & 0.01 & -0.11 & -0.05 \\
ALTDISTF & -0.02 & 0.00 & -0.13 & -0.04 \\
ALTDIFDIS & 0.11 & 0.06 & -0.01 & 0.10 \\
\hline & -0.02 & 0.01 & -0.11 & -0.05 \\
\hline & & & &
\end{tabular}


Table IV. Multiple regression equations for the precipitation variables.

\begin{tabular}{|c|c|}
\hline $\begin{array}{l}\text { Rainfall } \\
\text { variable }\end{array}$ & Regression model \\
\hline$S P R I$ & $\begin{array}{l}-43542.4+0.00000278245 \times C O A S T \times Z 5 \\
+184.045 \times V S \_N 1 \times A \_N 1+ \\
824.336 \times V S \_N 1 \times C \_N 1+0.0144214 \times \\
X \times C O N T 20+0.0000291517 \times X \times S 5+ \\
6.76583 E-8 \times X \times X-2.35964 E-8 \times X \times Y+ \\
0.0190231 \times Y-0.00223746 \times Y \times C O N T 20\end{array}$ \\
\hline SUMM & $\begin{array}{l}-8603.87+0.00205516 \times Y+440.75 \times \\
V S \_N 1+8.7703 E-7 \times X \times Z 10- \\
0.873644 \times Z 10 \times V S \_N 1\end{array}$ \\
\hline$A U T U$ & $\begin{array}{l}-419047.0-2.26915 \times D 5 \times V A N 1+ \\
59.5509 \times S 10 \times V S \_N 1+ \\
1050.29 \times V S \_N 1 \times V S \_E 1-0.0897704 \times X+ \\
0.00726557 \times X \times C \perp 1- \\
0.000989102 \times X \times C O N T 50+6.83902 E-8 \times \\
X \times X+0.20534 \times Y-0.00110563 \times \\
Y \times C N 1 \\
+0.000249489 \times Y \times C O N T 20+ \\
1.21971 E-7 \times Y \times D 5-2.34694 E-8 \times Y \times Y\end{array}$ \\
\hline WINT & $\begin{array}{l}-3330.77-2.94472 \times D 10 \times V S \_N 1+ \\
170.792 \times S 10 \times V S \_N 1+ \\
658.656 \times V A \_E 1 \times A \_N 1+2003.1 \times \\
V A \_N 1 \times A \_1+347.295 \times V S \_E 1 \times C \_N 1- \\
44263.7 \times V S \_E 1 \times V S \_E 1-9581.9 \times \\
V S \_N 1 \times V A \_1+77384.5 \times V S \_N 1 \times V S \_E 1 \\
+ \\
0.0304957 \times X \times C O N T 50+9.7314 E-7 \times \\
X \times D 10-0.0933675 \times X \times V S \_E 1+ \\
0.0848357 \times X \times V S \_N 1-1.54003 E-8 \times X \times Y \\
+6.90432 E-8 \times X \times X-0.00508842 \times \\
Y \times C O N T 50+0.000701751 \times Y \times V A N 1+ \\
0.0286533 \times Y \times V S \_E 1-0.0295974 \times \\
Y \times V S \_N 1\end{array}$ \\
\hline
\end{tabular}

In these equations, for example, the cross product between the variables $X$ and $Y$ are denoted by $X \times Y$ (units are in tenths of $\mathrm{mm}$ ).

cases. Moreover, the $Y$ appears alone in all models except in the WINT, where it is introduced multiplying $X$. In the case of the SPRI variable stands out the influence of the latitudinal $(Y)$ and longitudinal $(X)$ components, the synoptic flow on surface ( $V S N 1)$, and the continentally (CONT20). For the SUMM variable, the synoptic flow on surface (VS_N1), the elevation (Z10), and the latitude $(Y)$. For the $A U T U$ variable, the latitudinal component $(Y)$ - that appears alone and with squared product - , the longitudinal component $(X)$, the height difference (D5), the synoptic flow on surface (VS_N1 and VS_E1), the continentally (CONT2O and CONT50), and the direction to the shorter distance to the sea $\left(C_{-} N 1\right)$. For the WINT variable, the synoptic flows $(V S N 1$ and $V A N 1)$ and the latitudinal $(Y)$ and longitudinal $(X)$ components, mainly.

The computed semivariogram models for each of the rainfall variables are shown in Table V. For the SPRI and $A U T U$ variables, geometric anisotropies were considered. The SUMM and WINT variables were deemed to be
Table V. Computed semivariogram models for the kriging method.

\begin{tabular}{ll}
\hline Variable & \multicolumn{1}{c}{ Semivariogram } \\
\hline SPRI & $101.49 \times$ Nugget $+1212.1 \times$ Spherical(171290, \\
& $124800,294.5)$ \\
SUMM & $3.512 \times$ Nugget $+405.88 \times$ \\
& Spherical(179030)+276,64× Gaussian(179030) \\
AUTU & $255.89 \times$ Nugget $+3135.90 \times$ \\
& Gaussian(121940, 99840,115.7) \\
WINT & $9.7155 \times$ Nugget $+2903.80 \times$ \\
& Spherical(123770) \\
\hline
\end{tabular}

The equations are: $\hat{\gamma}(\mathbf{h})=$ nugget effect $+(\text { partial sill })_{1} \times$ Model $_{1}$. (major range $e_{1}$, minor range ${ }_{1}$, azimuth 1$)+(\text { partial sill })_{2} \times$ Model $_{2}$. (major range 2, minor range 2, azimuth $_{2}$ ). Precipitation units are in $\mathrm{mm}$.

Table VI. Computed semivariogram models for the residual kriging.

\begin{tabular}{ll}
\hline Variable & \multicolumn{1}{c}{ Semivariogram } \\
\hline SPRI & $200.11 \times$ Nugget $+45.017 \times$ \\
& Exponential(171330, 109360, 56.3) \\
SUMM & $31.638 \times$ Nugget $+50.438 \times$ Spherical $(24260)$ \\
$A U T U$ & $244.63 \times$ Nugget $+146.28 \times$ \\
& Exponential(24661) \\
WINT & $275.07 \times$ Nugget $+140.86 \times$ \\
& Exponential(171320,93886, 24.1) \\
\hline
\end{tabular}

The equations are: $\gamma(\mathbf{h})=$ nugget effect $+($ partial sill $) \times$ Model $($ major range, minor range, azimuth). Precipitation units are in $\mathrm{mm}$.

isotropic. A spherical model is used for the SPRI and WINT variables. The AUTU semivariogram is modelled by means a Gaussian model. For the $S U M M$ variable we use a combination of the spherical and Gaussian models.

The computed semivariogram models for the MRK interpolation are shown in Table VI. To obtain these parameters we have computed an experimental semivariogram considering a lag spacing equal to $10000 \mathrm{~m}$ and the number of lags equals 18 . Geometric anisotropy is considered for the SPRI and WINT variables, which have a range higher than that of the SUMM and AUTU variables.

Semivariogram and cross-covariance models for cokriging approaches are described in Table VII using the MRK model as secondary variable. For the SPRI, AUTU, and WINT variables geometric anisotropies were considered. The SUMM variable was deemed to be isotropic. As in the OK method we have chosen a spherical model for the SPRI and WINT variables. The AUTU semivariogram is modelled by means of a Gaussian model and the $S U M M$ variable uses a combination of the spherical and Gaussian models.

\subsection{Goodness of the model fit}

The degree of model accuracy was quantified using the following four statistical indicators: (1) the coefficient of determination $\left(R^{2}\right)$, where $R$ is the correlation coefficient 
Table VII. Computed semivariogram and cross-covariance models for the cokriging method.

\begin{tabular}{|c|c|}
\hline Variable & Computed models \\
\hline$S P R I$ & $\begin{array}{l}\text { Semivariogram: } 105.33 \times \text { Nugget }+1259 \times \\
\text { Spherical }(171290,132470,299) \\
\text { Cross-covariance: } 537.30 \times \\
\text { Spherical }(171290,132470,299) \\
\text { Secondary: } 18.875 \times \text { Nugget }+1231 \times \\
\text { Spherical }(171290,132470,299)\end{array}$ \\
\hline SUMM & 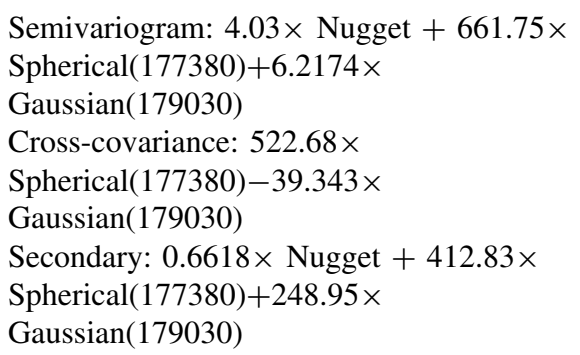 \\
\hline$A U T U$ & $\begin{array}{l}\text { Semivariogram: } 188.08 \times \text { Nugget }+ \\
3284.50 \times \text { Gaussian }(171290,78419,339) \\
\text { Cross-covariance: } 2026.80 \times \\
\text { Gaussian }(171290,78419,339) \\
\text { Secondary: } 75.562 \times \text { Nugget }+3127.50 \times \\
\text { Gaussian }(171290,78419,339)\end{array}$ \\
\hline WINT & $\begin{array}{l}\text { Semivariogram: } 0 \times \text { Nugget }+3199.6 \times \\
\text { Spherical }(171280,124740,317.7) \\
\text { Cross-covariance: } 1488.1 \times \\
\text { Spherical }(171280,124740,(317.7)) \\
\text { Secondary: } 0 \times \text { Nugget }+2909.4 \times \\
\text { Spherical }(171280,124740,317.7)\end{array}$ \\
\hline
\end{tabular}

The equations are: $\hat{\gamma}(\mathbf{h})=$ nugget effect $+(\text { partial sill })_{1} \times$ Model $_{1}$. $\left(\right.$ major range $_{1}$, minor range ${ }_{1}$, azimuth $\left._{1}\right)+(\text { partial sill })_{2} \times$ Model $_{2}$. (major range 2 , minor range 2 , azimuth $_{2}$ ). Precipitation units are in $\mathrm{mm}$.

between the predicted and the observed values; (2) the root mean square error (RMSE); (3) the mean absolute error (MAE); and (4) the mean relative percentage error (MRE\%). The numerical formulas are the following:

$$
\begin{aligned}
& \operatorname{RMSE}=\sqrt{\frac{1}{n} \sum_{i=1}^{n}\left(z_{i}^{*}-z_{i}\right)^{2}}, \quad \text { MAE }=\frac{1}{n} \sum_{i=1}^{n}\left|z_{i}^{*}-z_{i}\right|, \\
& M R E \%=\frac{1}{n} \sum_{i=1}^{n} \frac{\left|z_{i}^{*}-z_{i}\right|}{z_{i}} \cdot 100
\end{aligned}
$$

where $z_{i}$ is the ith-observed value, $z_{i}^{*}$ is the ith-predicted value, and $n$ is the total number of test observations. The determination coefficient $R^{2}$ is a quantity that gives the quality of a least squares fitting to the original data, and therefore can be included as a first calculation of the reliability of the model. Nevertheless, the relationship between $R^{2}$ and model performance is not well defined, and the magnitudes of $R^{2}$ are not consistently related to the accuracy of prediction. Therefore, the RMSE and $M A E$ were also calculated, being considered as the best overall measures of model performance, as they summarize the mean difference in the units of the
Table VIII. Statistics of the different interpolation methods for each climate station.

\begin{tabular}{lccrrr}
\hline & Method & $R^{2}$ & RMSE & MAE & MRE (\%) \\
\hline SPRI & MR & 0.78 & 14.13 & 11.10 & 9.19 \\
& OK & 0.81 & 13.33 & 9.75 & 7.34 \\
& MRK & 0.84 & 12.21 & 9.39 & 7.34 \\
& OCK & 0.81 & 13.31 & 9.69 & 7.29 \\
SUMM & MR & 0.93 & 8.12 & 5.56 & 7.63 \\
& OK & 0.95 & 6.65 & 4.80 & 6.49 \\
& MRK & 0.96 & 5.72 & 4.26 & 5.66 \\
& OCK & 0.95 & 6.56 & 4.78 & 6.53 \\
AUTU & MR & 0.83 & 20.49 & 15.84 & 9.95 \\
& OK & 0.91 & 15.08 & 10.76 & 6.43 \\
& MRK & 0.88 & 17.66 & 13.22 & 8.01 \\
\multirow{4}{*}{$W I N T$} & OCK & 0.91 & 14.56 & 11.00 & 6.51 \\
& MR & 0.75 & 19.89 & 15.06 & 13.38 \\
& OK & 0.84 & 16.28 & 11.97 & 9.52 \\
& MRK & 0.78 & 19.03 & 14.08 & 12.27 \\
& OCK & 0.85 & 16.06 & 11.69 & 9.27 \\
\hline
\end{tabular}

The best results are highlighted.

observed and predicted data. The difference between them is that RMSE places a lot of weight on high errors while MAE is less sensitive to extreme values (VicenteSerrano et al., 2003). MRE is used to compare results obtained in different precipitation variables.

We have reserved part of the initial data, $(20 \%$ of the total) to check the validity of the models. Therefore, models are achieved with $80 \%$ of the available data and the rest is used exclusively for model validity. In Table VIII the obtained values are shown.

\section{Discussion}

Results shown in Table VIII indicate that there is no optimum method to define the spatial model of mean precipitation corresponding to an area of complex climatology as is the studied here. In fact, it is observed that for the summer the most adequate method to characterize the precipitation model is the MRK, while for the winter it is the OCK. For the spring and autumn to state which method is the best is not so easy because depending on which parameter is used to measure them, results are better in one case or other. In general, to calibrate the goodness of fit of the model the RMSE will be mainly used.

Shown these results, it is understood that a further reflection is needed upon the issues that determine the potentiality and limitations of each one of the proposed methodologies. It is evident that the direct application of the model acquired within the MR is, in each case, unsatisfactory to characterize the rainfall model that is registered on the Valencia area. Actually, the calculated determination coefficients indicate that there is between the $12 \%$ and the $20 \%$ of the observed variability that is not explained by these models. This, in fact, should 
not surprise us because, if the equations that define the polynomial model are analysed, it is seen that the number of variables that are used is relatively high, which implies that there are lots the issues that significantly affect the distribution model of precipitations. It seems clear that, if several topographical and geographical factors do interact, it is more than probable that in a same location appear geographical factors that favour the rainfall together with others that make it difficult, and therefore, the model that can be obtained is, at the most, an approximation of a complex reality, which is inefficient for the characterization of details.

The use of the corrector element of the interpolated residuals (method MRK) significantly improves the results because, in part, it corrects the insufficiencies of the proposed regression model as it has been demonstrated in other studies (Ninyerola et al., 2000; Wilk and Andersson, 2000; Wotling et al., 2000; Vicente-Serrano et al., 2003). Such improvements show that in some cases the resulting model is - of the four proposed - the best. This is what happens in summer and, to a less extent, in spring, but not in winter and autumn. The precipitation distribution of these climate stations are better characterized when geostatistical techniques are used, working better with the adjustment made within the OCK approach (although in autumn the MAE and MRE of the OK are smaller). What reasons can explain these differences? In first place, it is significant that the MRK works better in those cases in which the number of topographical and geographical variables that enter in the MR models is smaller: within the summer model only four variables are considered and within spring nine, while in autumn we have used twelve variables and in winter eighteen variables are considered. A second aspect that is interesting is that, as can be seen in Table III, the correlation coefficients between geographical variables and the precipitation are significantly greater in the summer and spring than in autumn and winter. In fact, in summer there are eleven variables (without products) with a correlation better than 0.4 (in absolute value), in spring there are five and in winter and autumn only two. All these indicate that the geographical issues influence in a more determinate way the explanation of the summer and spring rainfalls and, to a less extent, the autumn and winter rainfalls.

The OCK method in the form here proposed, i.e. by using the model of the MRK as a second variable, gives less weight to the geographical and topographical factors and, therefore, more weight to the distribution of the punctual rainfall values registered at each raingauge. This would explain that in those periods of the year the rainfall origin is associated to factors potentially more different - as is the case of autumn and winter - and the approximation results are more appropriate. The use of the MRK as a secondary variable is a novelty which is necessary in our case, as the use of the elevation - which has been used by other authors (Goovaerts, 2000; Diodatto and Cecarrelli, 2005) - does not have much sense because $\mathrm{t} Z 5$ and/or $Z 10$ only has a significant relationship within precipitation in summer, $(r=0.72)$, the correlation coefficient for the rest of the seasons being inferior to 0.35 . Moreover, it might be said that except for areas of few extensions, the exclusive use of the elevation variable turns out to be very slightly expressive, like remains demonstrated by studies realized in different places. For example, Brunsdon et al. (2001) show that in Great Britain the elevation factor presents a major influence in the NW part than in the SE, due to the fact that the majority of the rainfalls are associated to the zonal flows of the W and NW. Even in areas with little extension, in cases where the rains come from flows of contrasted winds, the elevation stops are the most significant variables, as can be observed in Diodato (2005).

The parameter measured within the MRE allows us to compare results of the different climatic stations, showing the proportion between the error size and the registered precipitation values. This allows observing that the best model corresponds to that of the summer using the MRK. The autumn is the second best described model with very similar results regarding OK or OCK. Spring is slightly worse modelled (with results very similar in OCK, MRK, and OK) and the winter is the worse modelled one being much better the models acquired within geostatistical techniques that those within the MR. It has to be noticed that the goodness of fit of the model in winter is substantially different from autumn. The model fit in autumn - in OK as well as in OCK - is really good, with only a $6.5 \%$ of the error; meanwhile in winter these values reach the $9 \%$. The reason of this difference can be due to the behaviour of the spatial correlation described by the semivariogram models. Therefore, meanwhile in autumn the semivariogram model is gaussian - what implies less changes in the variability of precipitation to short distances - in winter it is better fitted to an spherical model, in which the variability of precipitations are more important in short distances. The analysis of the cokriging semivariogram for the winter shows that the nugget effect is cero (Table VII), indicating that the precipitation variability in distances shorter than $10 \mathrm{~km}$ is practically null. Due to that the regression model works on pixels of $1 \mathrm{~km}$, it is logical that it registers lots of variations in this magnitude order. This provokes that it is significantly worse fitted during this season than during the rest of the year, in which the precipitation variability in areas smaller than $10 \mathrm{~km}$ is more important.

Of the exposed results in Table VIII, it is clear that both interpolation models that work better are the MRK and the OCK. Therefore, we have considered plotting the errors described as

$$
\operatorname{BIAS}_{i}=\frac{z_{i}^{*}-z_{i}}{z_{i}} \cdot 100
$$

for each raingauge that have been used in the tests for each season (Figures 5-8). In spring, the MAE is smaller if MRK model is used; meanwhile the MRE is a slightly smaller if the OCK is used. The two locations where more significant errors do appear are in Ademuz and in the Betic range. From the analysis of Figure 5 

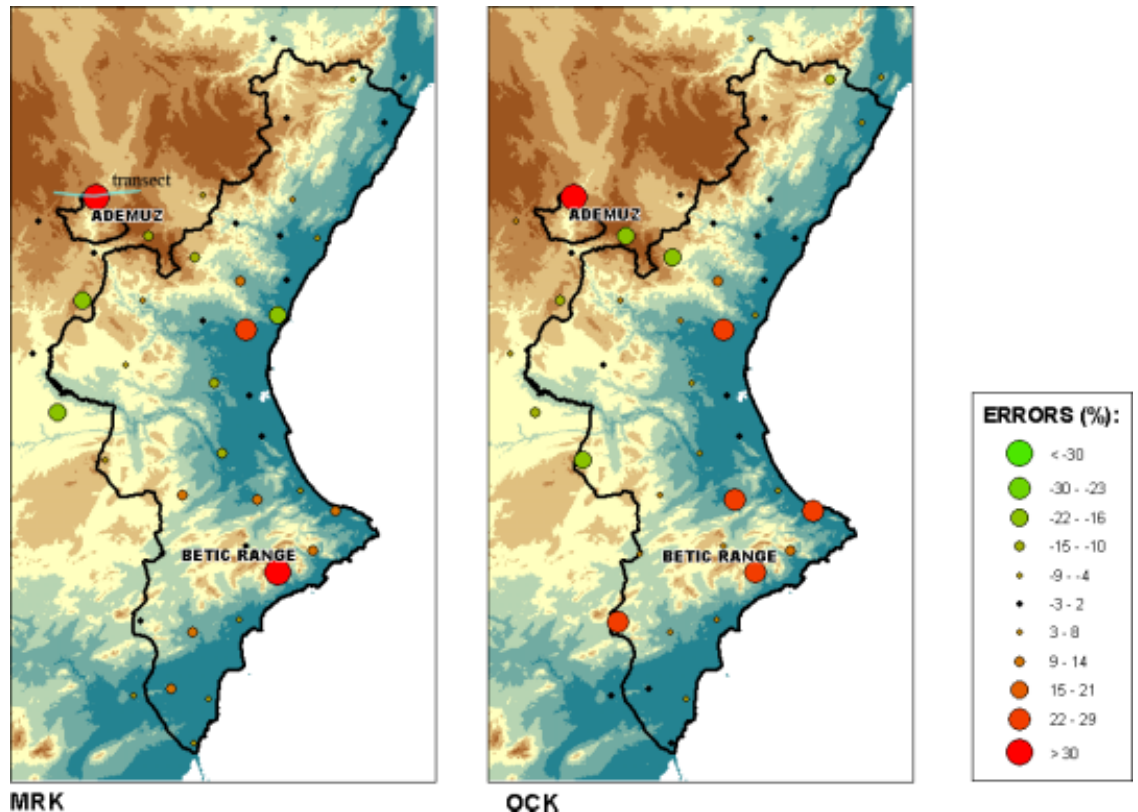

Figure 5. BIAS errors for the SPRI variable with the MRK and OCK methods. A transect is shown in the Ademuz area (see Figure 9). This figure is available in colour online at www.interscience.wiley.com/ijoc
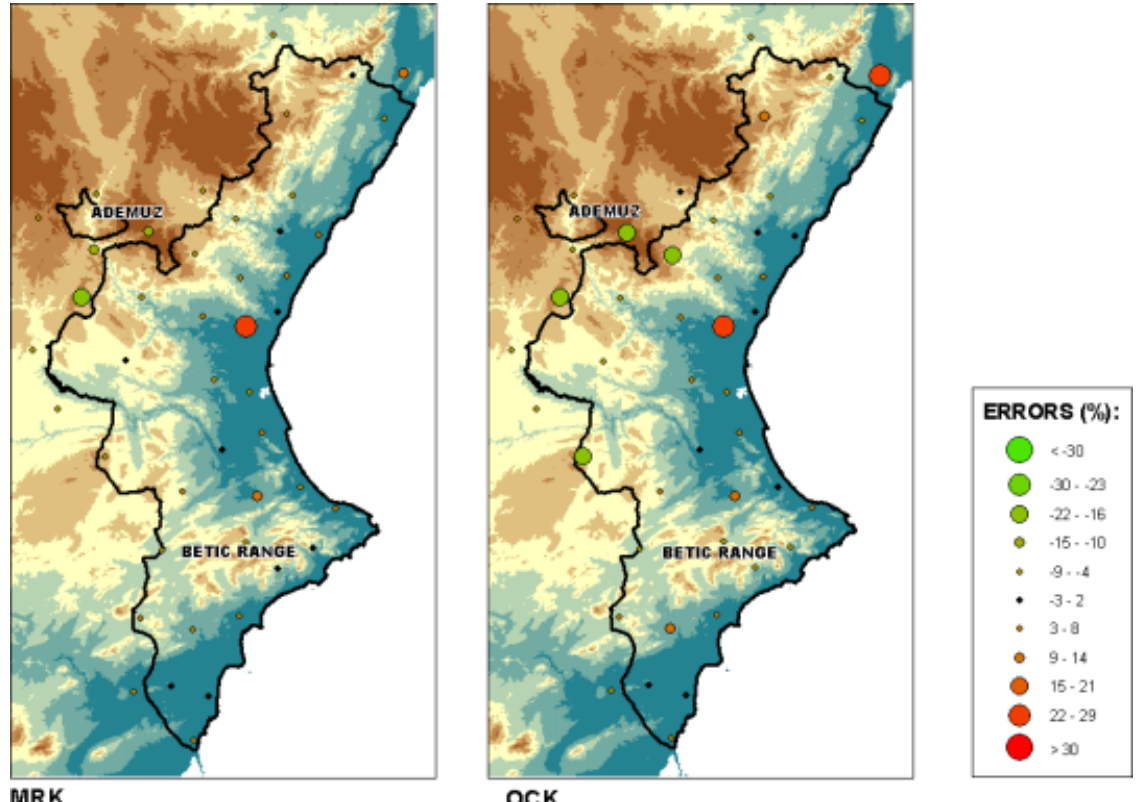

Figure 6. BIAS errors for the SUMM variable with the MRK and OCK methods. This figure is available in colour online at www.interscience.wiley.com/ijoc

it is deduced that with the OCK there is a location (close to Ademuz) with a BIAS error greater than in the MRK model. Furthermore, in the OCK model at the Betic ranges location, there appear four over valuated raingauges with more than $\pm 15 \%$ error, while in the MRK model there is only one raingauge with an error greater than $\pm 15 \%$, although this one is greater than its corresponding one in the OCK model. In summer, for both cases errors are in general quite small (Figure 6). In fact, for the MRK model - which is the model that works better - it is corroborated that the $89 \%$ of the considered raingauges do have a BIAS error smaller than $\pm 10 \%$. On the other hand, it is observed that in this model, only two raingauges do reach deviations from the estimated value by $\pm 15 \%$. In the OCK model, there are six raingauges with these conditions. In autumn (Figure 7) it is observed that the OCK model works better, as there is only one rainguge with errors reaching $\pm 23 \%$, while in the MRK model there are four raingauges with these characteristics. Finally, the winter (Figure 8) is the season worst modelled. In the MRK model, a location close to Ademuz has a BIAS error close to $\pm 75 \%$; these errors decrease to $\pm 58 \%$ in the OCK model. At the Betic area, the errors in the MRK do exceed $\pm 40 \%$. In fact, 


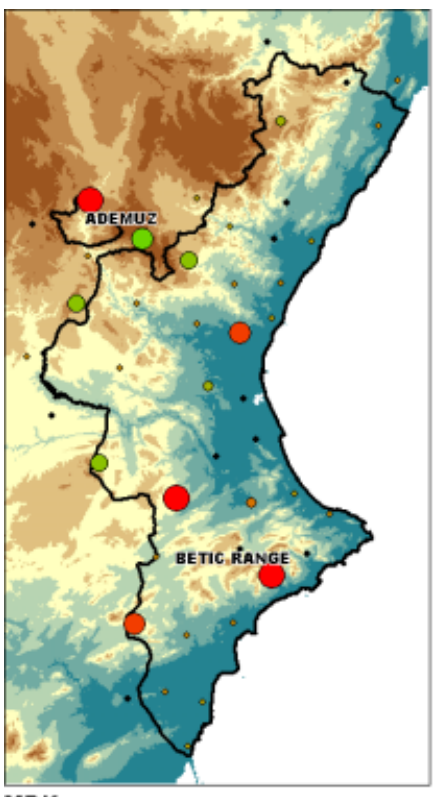

MRK
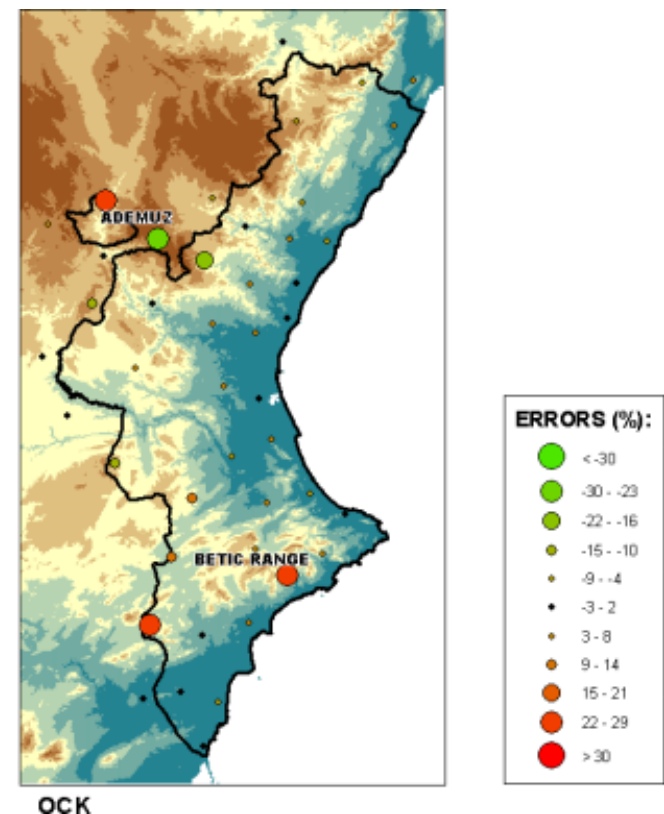

Figure 7. BIAS errors for the AUTU variable with the MRK and OCK methods. This figure is available in colour online at www.interscience.wiley.com/ijoc
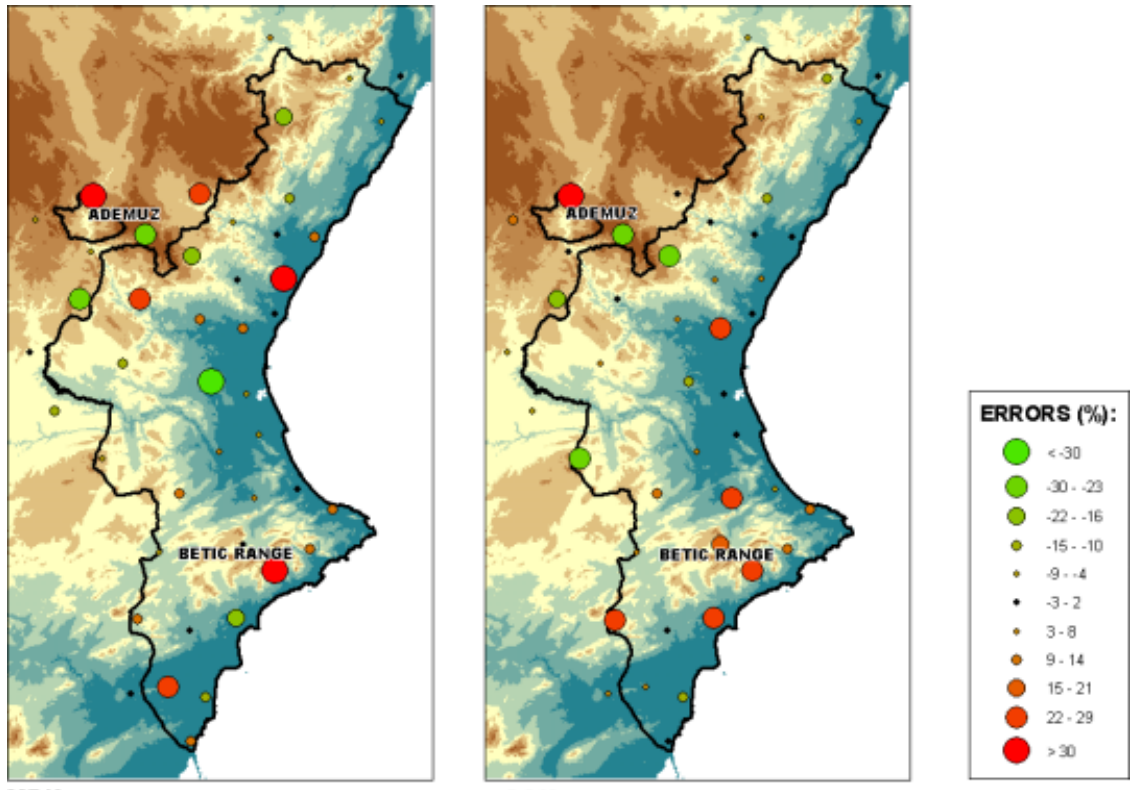

Figure 8. BIAS errors for the WINT variable with the MRK and OCK methods. This figure is available in colour online at www.interscience.wiley.com/ijoc

only a $53.2 \%$ of raingauges do have errors smaller than $\pm 10 \%$ in the MRK model; in the OCK, they represent $62.2 \%$ of the raingauges.

After the analysis of the generated maps, it is interesting to observe that, in most of cases - except for summer - the raingauges within greater BIAS errors are located at similar areas. It is an especially outstanding fact that the raingauge located close to Ademuz - overvaluated in all models except in both for the summer - has an error that can be related to a local effect. This raingauge is located at the bottom of a valley that has a N-S direction, being affected by an orographic shadow with respect to the wind fluxes coming from the sea. In summer, it is not affected because precipitations are not associated to sea winds, but they have a convective storms character. Figure 9 shows for the spring (Figure 9(a)) and autumn (Figure 9(b)), how the distribution of rainfall has been modelled and contrasted with the records measured in the raingauges. It is appreciated that in the case shown - a valley that presents a NS direction (in the area of Ademuz) - neither the MRK nor the OCK model is capable of recording the decrease in rainfall records that occurs in the bottom valley. The local orographic effects could also explain the systematic 

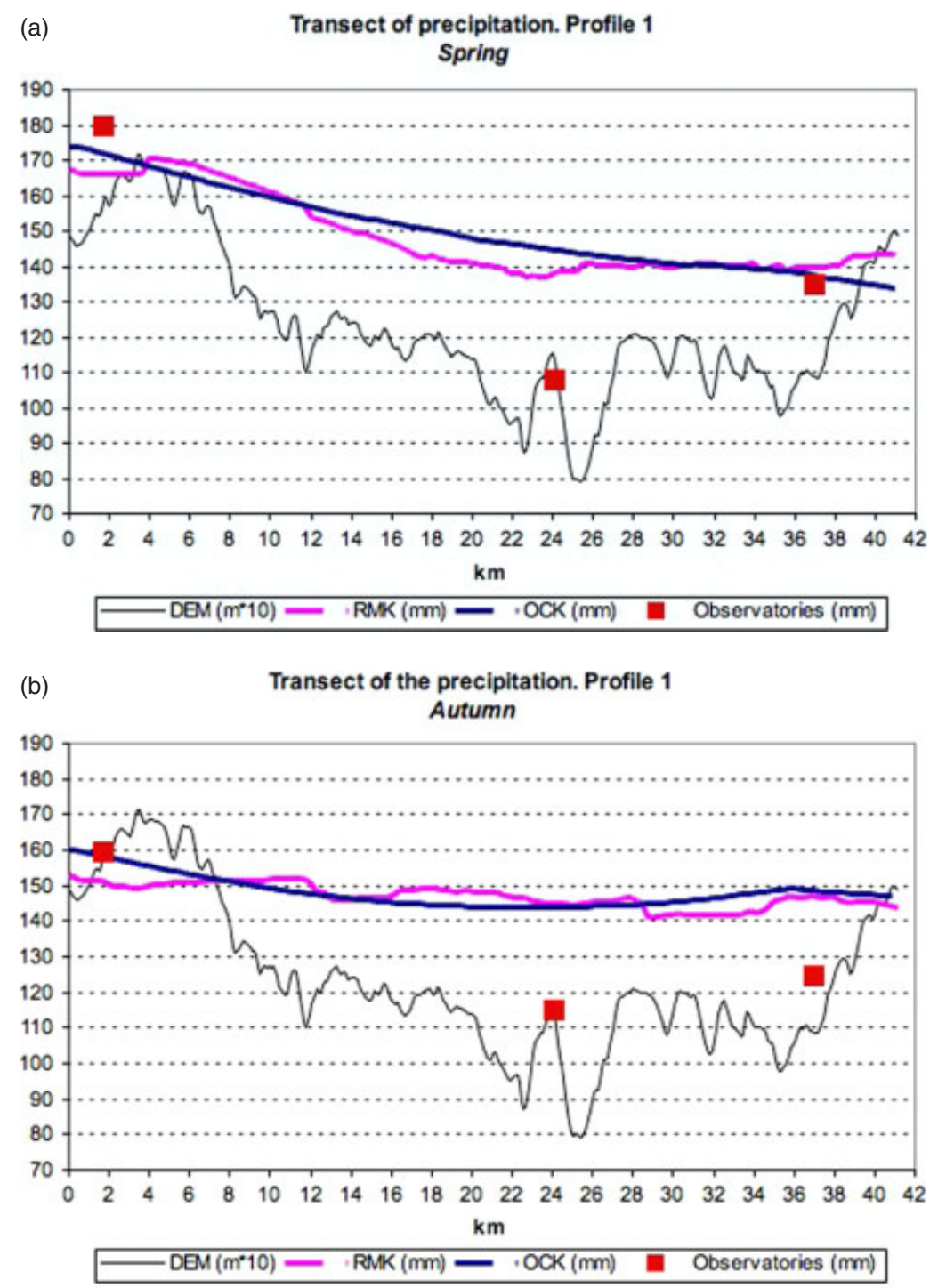

Figure 9. Transect perpendicular to the seashore in the Ademuz area (Turia valley) showing the interpolated precipitation for the MRK and OCK method and punctual measured data during (a) spring and (b) autumn. The transect position is shown in Figure 5. This figure is available in colour online at www.interscience.wiley.com/ijoc

errors that are registered at the locations close to the Betic ranges. On the other hand, it is interesting to emphasize that, in general and more clearly in the MRK model, the greater errors are related to the raingauges located at the more exterior regions of the study area; models do work relatively better at the central regions.

Of the exposed issues, it can be deduced that, despite the indicated limitations, the obtained results prove that the use of geographical and topographical information in most of the cases improve the capacity to deduce the rainfall in those places where there is a lack of data. This conclusion coincides with that expressed by many authors (Pardo-Igúzquiza, 1998; Goovaerts, 2000; Ninyerola et al., 2000; Wilk and Anderson, 2000; Johansson and Chen, 2003; Marquínez et al., 2003; Vicente-Serrano et al., 2003; Diodato and Ceccarelli, 2005). However, it can be observed that this improvement is evident in the case of summer but limited for the rest of seasons. The encountered limitations on the MR derived models imply some reflections of what is the spatial and temporal scale that is better adapted to this method and of the descriptive incapacity of some of the parameters used.

The detailed analysis of the errors at the meteorological stations allows to appreciate that the model overvalues the sample data in these locations because it does not take into consideration the effect of local orographic shadows caused by these valleys. Moreover, the study of the errors allow to appreciate that in the Betic areas the model undervalues the high precipitations that are registered in those places better oriented, while it overvalues the precipitation in those southern areas, provoking an undervaluation of the rainfall gradient here registered. These facts, together with the evidence that the variables related to orographic shadows are not significant in the model, make it necessary to reconsider the descriptive capacity of the parameters that try to valuate orographic shadows (the SUPDIFDIS and ALTDIFDIS parameters) or reconsider the used dimensions of the hillsides. On the other hand, it has to be understood that in those models in which a large number of variables take part, as discussed 
above, the weather nuances of local character will always be more difficult to characterize.

In any case, as the good results for the summer prove, the model would substantially improve in an homogeneous area, in that it exist a fewer number of factors that are related within the precipitation. This could be probably achieved by reducing as much the area as the period of analysis. Therefore, it could be much easy to characterize a rainfall event (instead of the mean precipitation) because the number of significant issues that would take place would be simplified, so that always the significant variables can be correctly identified.

\section{Conclusions}

In this study, four interpolation methods (univariate and multivariate estimators) have been tested to obtain the best distribution of the seasonal precipitation models for an area centred in the region of Valencia. A total of 25 topographical and/or geographical variables as well as the product between them were calculated for further analysis and possible inclusion into the multivariate estimators. The variables with major significance are the geographical longitude and latitude, the slope, as well as the orientation of the hillsides with regard to the North or East and with regard to the direction of the principal flows of winds that produce important rainfalls. Therefore, it is important to emphasize the importance of dividing the territory of analysis in real influence areas, as is the case of the hillsides. It is interesting to emphasize that the elevation factor is low correlated within mean precipitations, except for the summer.

It can be concluded that the multiple regression (MR) interpolation when used alone should be rejected as an unreliable model to interpolate the rainfall variable, at least in an area such as the region of Valencia, if residuals are not treated in further analysis. In case it is corrected by the residuals the obtained model can be extremely adaptable always and when there are not too many number of geographical variables in its definition. This would be the case of the summer model that manages to explain adequately the $88 \%$ of the rainfall variability with four secondary variables. The geostatistical methods - especially the cokriging method using as secondary variable the MRK model - are specially adapted for those situations in which many secondary variables exist concerning the rainfall. For these cases, the forecasting capacity of the method will improve when the rainfall presents a high spatial correlation at short distances.

\section{Acknowledgements}

This study is supported by the CTM2006-11767 y CLG2006-11242-C03/BTE Tecno projects of the Education and Science Ministry of Spain and FEDER funding. Our special acknowledgements are to Dr. A.J. Pérez Cueva for his valuable advice. We also would like to thank the observations made by two anonymous reviewers.

\section{References}

Agnew M, Palutikof JP. 2000. GIS-based construction of baseline climatologies for the Mediterranean using terrain variables. Climate Research 14(2): 115-127, DOI: 10.3354/cr014115.

Alcover VY, Tamayo CJ. 1994. Tempestes. In Atlas Climàtic de la Comunitat Valenciana (1961-1990). Pèrez-Cueva AJ (ed) Conselleria d'Obres Públiques, Urbanisme i Transports, Generalitat Valenciana: 56-57.

Andersson T. 1980. Bergeron and the oreigenic (orographic) maxima of precipitation. Pure and Applied Geophysics 119(3): 558-576, DOI: 10.1007/BF00878160.

Armengot-Serrano R. 1993. Marco sinóptico y distribución espacial de las precipitaciones intensas en la Comunidad Valenciana (1976-90). Diploma Thesis. Universidad de Valencia, Valencia, Spain.

Armengot-Serrano R. 1994. Temporals de llevant. In Atlas Climúàtic de la Comunitat Valenciana (1961-1990). Pèrez-Cueva AJ (ed.) Conselleria d'Obres Pú, Urbanisme i Transports, Generalitat Valenciana: 50-51.

Armengot-Serrano R. 2002. Las lluvias intensas en la Comunidad Valenciana. Ministerio de Medio Ambiente: 263.

Barry RG, Chorley RJ. 1984. Atmósfera, tiempo y clima. Ediciones Omega: Barcelona.

Brezonik PL, Stadelmann TH. 2002. Analysis and predictive models of stormwater runoff volumes, loads, and pollutant concentrations from watersheds in the Twin Cities metropolitan area, Minnesota, USA. Water Research 36(7): 1743-1757, DOI: 10.1016/S00431354(01)00375-X.

Brunsdon C, McClatchey J, Unwin DJ. 2001. Spatial variations in the average rainfall-altitude relationship in Great Britain: an approach using geographically weighted regression. International Journal of Climatology 21(4): 455-466, DOI: 10.1002/joc.614.

Burrough PA. 2001. GIS and geostatistics: essential partners for spatial analysis. Environmental and Ecological Statistics 8(4): 361-377, DOI: 10.1023/A:1012734519752.

Cano D, Tèllez B, Palacio JI, Arias P. 2001. Estudio de las zonas más favorables para el desarrollo de tormentas en la meseta meridional. In El tiempo y el clima. Pèrez-Cueva AJ, López-Baena E, Tamayo J (eds). Asociación Española de Climatología: 313-324.

Capdevilla SM, Pardo-Pascual JE, Porres de la Haza MJ, Palomar Vázquez J. 2003. Determinación automática de laderas a partir de un modelo digital de elevaciones. IX Conferencia Iberoamericana de SIG: De lo Local a lo Global. Nuevas Tecnologías de la Información Geográfica para el Desarrollo, Cáceres, Spain, 100-112.

Daly C, Gibson WP, Taylor GH, Johnson GL, Pasteris P. 2002. A knowledge-based approach to the statistical mapping of climate. Climate Research 22(2): 99-112, DOI: 10.3354/cr022099.

Daly C, Neilson RP, Phillips DL. 1994. A Statistical-Topographic Model for Mapping Climatological Precipitation over Mountainous Terrain. Journal of Applied Meteorology 33(2): 140-158, DOI: 10.1175/1520-0450(1994)033<0140:ASTMFM > 2.0.CO;2.

De Luís M, Raventós J, González-Hidalgo JC, Sánchez JR, Cortina J. 2000. Spatial analysis of rainfall trends in the region of Valencia (East Spain). International Journal of Climatology 20(12): 1451-1469, DOI: 10.1002/joc.547.

Deutsch CV, Journel AG. 1998. GSLIB: Geostatistical Software Library and User's Guide. Oxford University Press: New York.

Dingman SL, Seely-Reynolds DM, Reynolds RC. 1988. Application of kriging to estimate mean annual precipitation in a region of orographic influence. Water Resources Bulletin 24(2): 329-339, DOI: $10.1111 / \mathrm{j} .1752-1688.1988 . t b 02991 . x$.

Diodato N. 2005. The influence of topographic co-variables on the spatial variability of precipitation over small regions of complex terrain. International Journal of Climatology 25(3): 351-363, DOI: $10.1002 /$ joc. 1131.

Diodato N, Ceccarelli M. 2005. Interpolation processes using multivariate geostatistics for mapping of climatological precipitation mean in the Sannio Mountains (southern Italy). Earth Surface Processes and Landforms 30(3): 259-268, DOI: 10.1002/esp.1126.

Evrendilek F, Ertekin C. 2008. Assessing solar radiation models using multiple variables over Turkey. Climate Dynamics 31(2-3): 131-149, DOI: 10.1007/s00382-007-0338-6.

Font Tullot I. 1983. Climatología de España y Portugal. Instituto Nacional de Meteorología: Madrid.

Gibson WP, Daly C, Taylor GH. American Meteorological Society. 1997. Derivation of facets grids for use with the PRISM model Proceedings of the 10th AMS Conference on Applied Climatology, Reno, October 20-23, 208-209. 
Goodale CL, Aber JD, Ollinger SV. 1998. Mapping monthly precipitation, temperature, and solar radiation for Ireland with polynomia regression and a digital elevation model. Climate Research 10(1): 35-49, DOI: $10.3354 / \mathrm{cr} 010035$.

Goovaerts P. 1997. Geostatistics for Natural Resources Evaluation. Oxford University Press: New York.

Goovaerts P. 2000. Geostatistical approaches for incorporating elevation into the spatial interpolation of rainfall. Journal of Hydrology 228(1-2): 113-129, DOI: 10.1016/S0022-1694(00)00144-X.

Guijarro JA. 1997. Some climatological aspects of heavy rainfall in Mediterranean Spain. Simposio Internacional INM/OMM sobre cyclones y tiemnpo adverso en el Mediterráneo Palma de Mallorca, Ministerio de Medio Ambiente: 377-383.

Hevesi JA, Flint AL, Istok JD. 1992. Precipitation Estimation in Mountainous Terrain Using Multivariate Geostatistics. Part I: Structural Analysis. Journal of Applied Meteorology 31(7): 661-676, DOI: $10.1175 / 1520-0450(1992) 031<0677$ :PEIMTU > 2.0.CO;2.

HMSO. 1962. Whether in the Mediterrenean I: General Meteorology. HSMO: London, 362.

Huffman GF, Adler RF, Bolvin DT, Gu G, Nelkin EJ, Bowman KP, Hong Y, Stocker EF, Wolff DB. 2007. The TRMM Multisatellite precipitation analysis (TMPA): Quasi-global, multiyear, combined-sensor precipitation estimates at fine scales. Journal of Hidrometeorology 8: 38-55, DOI: 10.1175/JHM560.1.

Islam MN, Islam AKMS, Hayashi T, Terao T, Uyeda H. 2002. Application of a method to estimate rainfall in Bangladesh using GMS-5 data. Journal of Natural Disaster Science 24(2): 83-89.

Jansá. 1996. Ciclogénesis y lluvia fuerte en el Mediterráneo, hechos, incertidumbres y problemas. III Simposio Nacional de Predicción del INM. Madrid, 531-539.

Jansá A, Genovès A, Riosalido R, Carretero O. 1996. Mesoscale cyclones vs heavy rain and MCS in the Western Mediterranean MAP Newsl 5: 24-25.

Johansson B, Chen D. 2003. The influence of wind and topography on precipitation distribution in Sweden: statistical analysis and modelling. International Journal of Climatology 23(12): 1523-1535, DOI: $10.1002 /$ joc. 951 .

Johnston K, Ver Hoef JM, Krivoruchko K, Lucas N. 1997. Using ArcGIS geostatistical analyst: [ArcGIS 8]. ESRI: Redlands.

Lanza LG, Ramírez JA, Todini E. 2001. Stochastic rainfall interpolation and downscaling. Hydrology and Earth System Sciences 5(2): $139-143$.

Lin GF, Chen LH. 2003. A spatial interpolation method based on radial basis function networks incorporating a semivariogram model. Journal of Hydrology 288(3-4): 288-298, DOI: 10.1016/j.jhydrol.2003.10.008.

Mardikis MG, Kalivas DP, Kollias VJ. 2005. Comparison of interpolation methods for the prediction of reference evapotranspiration - an application in Greece. Water Resources Management 19: 251-278, DOI: $10.1007 / \mathrm{s} 11269-005-3179-2$.

Marquínez J, Lastra J, García P. 2003. Estimation models for precipitation in mountainous regions: the use of GIS and multivariate analysis. Journal of Hydrology 270(1-2): 1-11, DOI: 10.1016/S0022-1694(02)00110-5.

Martín-Vide J, Olcina Cantos J. 2001. Climas y tiempos de España. Alianza Editorial: 258

Montecinos A, Díaz A, Aceituno P. 2000. Seasonal diagnostic and predictability of rainfall in subtropical South America based on tropical pacific SST. Journal of Climate 13: 746-758, DOI: 10.1175/1520-0442(2000)013<0746:SDAPOR $>2.0 . \mathrm{CO} ; 2$

New M, Hulme M, Jones P. 2000. Representing twentieth-century space - time climate variability. Part II: development of 1901-1996 monthly grids of terrestrial surface climate. Journal of Climate 13: 2217-2238, DOI: $10.1175 / 1520-0442(2000) 013<2217$ : RTCSTC $>2.0 . \mathrm{CO} ; 2$.

New M, Todd M, Hulme M, Jones P. 2001. Precipitation measurements and trends in the twentieth century. International Journal of Climatology 21(15): 1899-1922, DOI: 10.1002/joc.680.

Ninyerola M, Pons X, Roure JM. 2000. A methodological approach of climatological modelling of air temperature and precipitation through GIS techniques. International Journal of Climatology 20(14): 1823-1841, DOI: $10.1002 /$ joc. 566.

Palmieri S, D'Aprano L, Siani AM. 1994. Diagnostic modeling of orographic and convective rainfall. Proceedings 23rd ITAM, Lindau, Germany.

Palomar-Vázquez JM, Pardo-Pascual JE, Porres de la Haza MJ. 2005. Generalization of high-density raster Digital Elevation Models.
Proceedings International Cartographic Conference: Mapping approaches into a changing World. A Coruña (Spain), publication in CD-ROM, 10 pages.

Pannatier I. 1996. VARIOWIN. Software for Spatial Data Analysis in 2D. Springer: New York.

Pardo-Igúzquiza E. 1998. Comparison of geostatistical methods for estimating the areal average climatological rainfall mean using data on precipitation and topography. International Journal of Climatology 18(9): 1031-1047, DOI: 10.1002/joc.303.

Peñarrocha FD. 1994. La precipitación amb temporals de l'oest. In Atlas climàtic de la Comunitat Valenciana (1961-1990), PèrezCueva AJ (ed). Conselleria d'Obres Públiques, Urbanisme i Transports, Generalitat Valenciana: 54-55.

Pérez Cueva AJ. 1994a. Atlas Climático de la Comunidad Valenciana. Serie: Publicaciones de divulgación técnica. Colección: "Territori" (4). Generalitat Valenciana: Valencia.

Pèrez Cueva AJ. 1994b. Marc climàtic i dinàmica atmosfèrica mediterrania. In Atlas climàtic de la Comunitat Valenciana (1961-1990), Pèrez-Cueva AJ (ed.) Conselleria d'Obres Públiques, Urbanisme i Transports, Generalitat Valenciana: 36-37.

Price DT, McKenney DW, Nalder IA, Hutchinson MF, Kesteven JL. 2000. A comparison of two statistical methods for spatial interpolation of Canadian monthly mean climate data. Agricultural and Forest Meteorology 101(2-3): 81-94, DOI: 10.1016/S01681923(99)00169-0.

Prudhomme C, Reed DW. 1999. Mapping extreme rainfall in a mountainous region using geostatistical techniques: a case study in Scotland. International Journal of Climatology 19(12): 1337-1356, DOI: 10.1002/(SICI) 1097-0088(199910)19: 12<1337::AID-JOC421> 3.0.CO;2-G.

Rigo T. 2004. Estudio de Sistemas Convectivos Mesoscalares en la zona Mediterránea Occidental Mediante el uso del Radar Meteorológico. PhD thesis, Universitat de Barcelona.

Rigo T, Llasat MC. 2007. Analysis of mesoscale convective systems in Catalonia using meteorological radar for the period 1996-2000. Atmospheric Research 83: 458-472.

Riosalido R. 1997. Mesoscale convective systems in western Mediterranean area: a satellite view. Proceedings of the Simposio Internacional INM/OMM sobre Ciclones y Tiempo Adverso en el Mediterráneo, Palma de Mallorca, Spain, 14-17 April, 353-359.

Riosalido R, Elizaga F, Carretero O, Martín F. 1998. Climatología de Sistemas Convectivos de Mesoescala en las proximidades de la Península Ibérica: Aplicaciones a la predicción de lluvias torrenciales. Proyecto CICYTCLI95-1776. Thecnical Note of STAP, 29. Spanish Weather Service. May 1998.

Sboarina C. 2002. Development of a complete climate database using a new GRASS module. Proceedings of the Open Source GIS, GRASS Users Conference. Trento, Italy, 11-13 September.

Sotillo MG, Ramis C, Romero R, Alonso S, Homar V. 2003. Role of orography in the spatial distribution of precipitation over the Spanish Mediterranean zone. Climate Research 23(3): 247-261, DOI: $10.3354 / \mathrm{cr} 023247$.

Su F, Hong Y, Lettenmaier DP. 2008. Evaluation of TRMM Multisatellite precipitation analysis (TMPA) and its utility in hidrologic prediction in the Plata basin. Journal of Hydrometeorology 9: 622-640, DOI: 10.1175/2007JHM944.1

Vajda A, Venalainen A. 2003. The influence of natural conditions on the spatial variation of climate in Lapland, northern Finland. International Journal of Climatology 23(9): 1011-1022, DOI: 10.1002/joc.928.

Vicente-Serrano SM, Saz-Sánchez MA, Cuadrat JM. 2003. Comparative analysis of interpolation methods in the middle Ebro Valley (Spain): application to annual precipitation and temperature. Climate Research 24(2): 161-180, DOI: 10.3354/cr024161.

Wetzel SW, Martin JE. 2001. An operational ingredients-based methodology for forecasting midlatitude winter season precipitation. Weather and Forecasting 16(1): 156-167, DOI: 10.1175/15200434(2001)016<0156:AOIBMF> 2.0.CO;2.

Wilk J, Andersson L. 2000. GIS-supported modelling of rainfall in a mountainous river basin with monsoon climate in southern India. Hydrological Sciences 45(2): 185-201.

Wotling G, Bouvier Ch, Danloux J, Fritsch JM. 2000. Regionalization of extreme precipitation distribution using the principal components of the topographical environment. Journal of Hydrology 233(1-4): 86-101, DOI: $10.1016 / \mathrm{S} 0022-1694(00) 00232-8$. 